\title{
A porcine model of neurofibromatosis type 1 that mimics the human disease
}

Katherine A. White, ${ }^{1}$ Vicki J. Swier, ${ }^{1}$ Jacob T. Cain, ${ }^{1}$ Jordan L. Kohlmeyer, ${ }^{2}$ David K. Meyerholz, ${ }^{3}$ Munir R. Tanas, ${ }^{3}$ Johanna Uthoff,, ${ }^{4,5}$ Emily Hammond, ${ }^{4,5}$ Hua Li, ${ }^{6,7}$ Frank A. Rohret, ${ }^{8}$ Adam Goeken, ${ }^{3}$ Chun-Hung Chan, ${ }^{1}$ Mariah R. Leidinger, ${ }^{3}$ Shaikamjad Umesalma, ${ }^{9}$ Margaret R. Wallace, ${ }^{6,7}$ Rebecca D. Dodd, ${ }^{10,11}$ Karin Panzer, ${ }^{12}$ Amy H. Tang, ${ }^{13}$ Benjamin W. Darbro, ${ }^{11,12}$ Aubin Moutal, ${ }^{14}$ Song Cai, ${ }^{14}$ Wennan Li, ${ }^{14}$ Shreya S. Bellampalli, ${ }^{14}$ Rajesh Khanna, ${ }^{14}$ Christopher S. Rogers, ${ }^{8}$ Jessica C. Sieren, ${ }^{4,5,11}$ Dawn E. Quelle, ${ }^{2,3,9,11}$ and Jill M. Weimer ${ }^{1,15}$

'Pediatrics and Rare Diseases Group, Sanford Research, Sioux Falls, South Dakota, USA. 'Molecular Medicine Program, ${ }^{3}$ Department of Pathology, and ${ }^{4}$ Department of Radiology, University of lowa Carver College of Medicine, lowa City, lowa, USA. ${ }^{5}$ Department of Biomedical Engineering at the University of lowa, lowa City, lowa, USA. ${ }^{6}$ Department of Molecular Cenetics and Microbiology and 'University of Florida Health Cancer Center, University of Florida, Gainesville, Florida, USA. ${ }^{8}$ Exemplar Genetics, Coralville, lowa, USA. ${ }^{9}$ Department of Pharmacology and ${ }^{10}$ Department of Internal Medicine, University of lowa Carver College of Medicine, lowa City, lowa, USA. "'Holden Comprehensive Cancer Center, University of lowa, lowa City, lowa, USA. ${ }^{12}$ Department of Pediatrics, University of lowa Carver College of Medicine, lowa City, lowa, USA. ${ }^{13}$ Department of Microbiology and Molecular Cell Biology, Leroy T. Canoles Jr. Cancer Research Center, Eastern Virginia Medical School, Norfolk, Virginia. ${ }^{14}$ Department of Pharmacology, University of Arizona, Tucson, Arizona, USA. ${ }^{15}$ Department of Pediatrics, Sanford School of Medicine at the University of South Dakota, Sioux Falls, South Dakota, USA.

Loss of the NF1 tumor suppressor gene causes the autosomal dominant condition, neurofibromatosis type 1 (NF1). Children and adults with NF1 suffer from pathologies including benign and malignant tumors to cognitive deficits, seizures, growth abnormalities, and peripheral neuropathies. NF1 encodes neurofibromin, a Ras-CTPase activating protein, and NF1 mutations result in hyperactivated Ras signaling in patients. Existing NF1 mutant mice mimic individual aspects of NF1, but none comprehensively models the disease. We describe a potentially novel Yucatan miniswine model bearing a heterozygotic mutation in NF1 (exon 42 deletion) orthologous to a mutation found in NF1 patients. NF(1/exazdel miniswine phenocopy the wide range of manifestations seen in NF1 patients, including café au lait spots, neurofibromas, axillary freckling, and neurological defects in learning and memory. Molecular analyses verified reduced neurofibromin expression in swine $\mathbf{N F}^{+/ \text {exazdel }}$ fibroblasts, as well as hyperactivation of Ras, as measured by increased expression of its downstream effectors, phosphorylated ERK1/2, SIAH, and the checkpoint regulators $\mathrm{p} 53$ and p21. Consistent with altered pain signaling in NF1, dysregulation of calcium and sodium channels was observed in dorsal root ganglia expressing mutant NF1. Thus, these $\mathrm{NF}^{+/ \text {exazdel }}$ miniswine recapitulate the disease and provide a unique, much-needed tool to advance the study and treatment of NF1.

Authorship note: CSR, JCS, DEQ, and JMW are co-senior authors.

Conflict of interest: The authors have declared that no conflict of interest exists.

Submitted: February 8, 2018

Accepted: May 17, 2018

Published: June 21, 2018

\section{Reference information:} JCI Insight. 2018;3(12): e120402. https://doi.org/10.1172/jici. insight.120402.

\section{Introduction}

Neurofibromatosis type 1 (NF1) is an autosomal dominant disorder caused by mutations in the neurofibromin 1 (NF1) gene that affect approximately 1 in 3,500 individuals worldwide. NF1 belongs to the RASopathy group of genetic syndromes caused by germline mutations in genes that regulate the Ras/ MAPK pathway. Neurofibromin, the protein product of the NF1 gene, is a tumor suppressor that inhibits Ras signaling through its Ras-GTPase activating protein (Ras-GAP) activity (1-6). NF1 has more than 1,000 disease-associated mutations identified in patients. As such, the disease is quite heterogeneous in presentation, manifesting a variety of symptoms including abnormal pigmentation in the form of café au lait spots and auxiliary freckling; growth deformities and chronic idiopathic pain; neurological complications such as cognitive impairment, seizures, and uncontrolled migraines; tumor growth; and predisposition to cancer (7-11). NF1 tumors are primarily benign and present as small, cutaneous neurofibromas 
or large, plexiform neurofibromas that can span over entire body segments, causing significant morbidity due to their size and/or location. However, $10 \%-15 \%$ of NF1 patients develop malignancies including gliomas, leukemia, and malignant peripheral nerve sheath tumors (MPNSTs) that arise via transformation of precursor plexiform neurofibromas $(12,13)$.

In recent years, there has been a call from the NF1 research community for improved models of the disease to better understand the essential molecular mechanisms underlying the pathogenesis of NF1. In the early 1990s, 2 groups developed mice with a null mutation in Nf1 exon 40 (which, at the time, was annotated as exon 31), a mutational hotspot in patients $(14,15)$ (reviewed in ref. 16). Homozygous inactivation of $N f 1$ caused embryonic lethality while $N f 1$ heterozygous mice were viable and tumor prone but failed to develop many of the common disease features observed in human NF1. Specifically, Nf1 heterozygous mice developed pheochromocytoma and myeloid leukemia but lacked the classic NF1 tumors, skin pigmentation abnormalities, and Lisch nodules and enhanced pain perception $(14,15,17,18)$ (reviewed in ref. 19). Since that time, additional compound- and tissue-specific mutant mice expressing various $N f 1$ mutations combined with other gene alterations have been developed $(4,20)$. For instance, compound heterozygotic mice lacking $N f 1$ along with other tumor suppressor genes frequently mutated in NF1-associated tumors (such as $p 53$ or $I N K 4 a / A R F$ ) develop MPNSTs with high penetrance (21-25), effectively establishing the importance of $N f 1$ in tumor suppression. Despite these important advances, the NF1 community has lacked an Nf1 heterozygote animal model that fully mimics the human disease without additional genetic mutations.

Here, we describe the generation of the first miniswine model of NF1 to our knowledge that has a deleted $N F 1$ exon 42 on 1 allele (designated $N F 1^{+/ \text {ex } 42 d e}$ ). Swine have proven to be an excellent model organism due to their relatively fast maturation rate, large number of offspring per sow each year, and similarities with human anatomy, biochemistry, physiology, size (particularly miniature swine breeds), lifespan, and genetics (reviewed in ref. 26). Indeed, previous studies from our group and others have demonstrated the utility of swine as a powerful and accurate model for obesity, diabetes, alcoholism, hypertension, skin physiology, intestinal function, nutrition, and injury (reviewed in refs. 27, 28). For example, cystic fibrosis swine models were successful in demonstrating the range of clinical manifestations of the human disease, including meconium ileus, pancreatic insufficiency, and lung disease (29-32). Similar success has been obtained with our recent models of atherosclerosis, cancer, a common cardiac arrhythmia, and ataxia telangiectasia (33-36). In the context of NF1, a swine model provides the unique ability to monitor disease progression on human-grade imaging equipment, an important aspect of clinically managing tumor growth and treatment planning in NF1 patients.

At birth, these $N F 1^{+/ \text {ex42del }}$ animals present with skin pigmentation changes characteristic of café au lait spots. At the cellular level, inactivation of swine neurofibromin recapitulates the defects in Ras signaling and ion channel regulation associated with the disease, and over a period of months, these animals develop additional classic indicators of NF1, namely neurofibromas and axillary/inguinal freckling. By 10 months of age, the $N F 1^{+ \text {eex } 42 d e l}$ miniswine display impaired learning and memory. This innovative model recapitulates the wide spectrum of the phenotypic and pathological changes associated with the human disease, providing an invaluable tool to accelerate NF1 research and therapies.

\section{Results}

NF1 mutant miniswine generation and café au lait macule characterization. $N F 1^{+/ \text {ex42del }}$ Yucatan miniature swine (miniswine) were generated via recombinant adeno-associated virus-mediated (rAAV-mediated) gene targeting and somatic cell nuclear transfer (SCNT) using methods described previously (33-37). Briefly, male Yucatan fetal fibroblasts were infected with rAAV carrying a targeting construct designed to replace the endogenous NF1 exon 42 with a blasticidin resistance cassette (Blast ${ }^{\mathrm{R}}$ ) (Figure 1A). In a subsequent step, the cassette was removed via Cre recombinase-mediated excision. The resulting $N F 1^{+/ \text {ext2del }}$ fibroblasts were used as nuclear donors for SCNT. The genotype of each miniswine produced was confirmed by PCR and Southern blot (Figure 1, B and C, respectively), as well as by DNA sequencing (data not shown).

A common NF1 feature in humans is the presence of café au lait macules, axillary/inguinal freckling, and cutaneous tumors. In the $N F 1^{+/ e x t 2 d e l}$ miniswine, skin pigmentation changes indicative of these café au lait macules, inguinal freckling, and cutaneous tumors were present and were distinct from uncommon pigmentation in control animals (Figure 1, D-H). In fact, the café au lait macules were present at birth and were present in $100 \%$ of $N F 1^{+/ \text {ex42del }}$ miniswine (Table 1). The cutaneous lesions were present in $44 \%$ of $N F 1^{+/ e x 42 d e l}$ miniswine, appearing from 11-17 months of age (Figure 2 and Table 1). These lesions were examined by histopathology and compared with adjacent unaffected skin. In $N F 1^{+/ \text {ext2del }}$ skin biopsies, the macules showed increased 
A

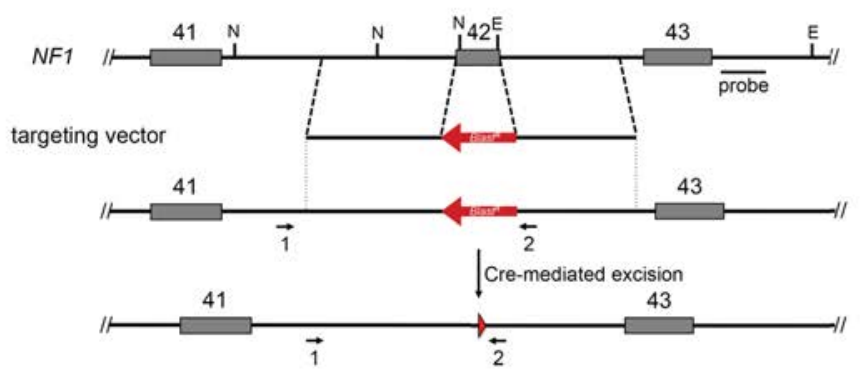

B
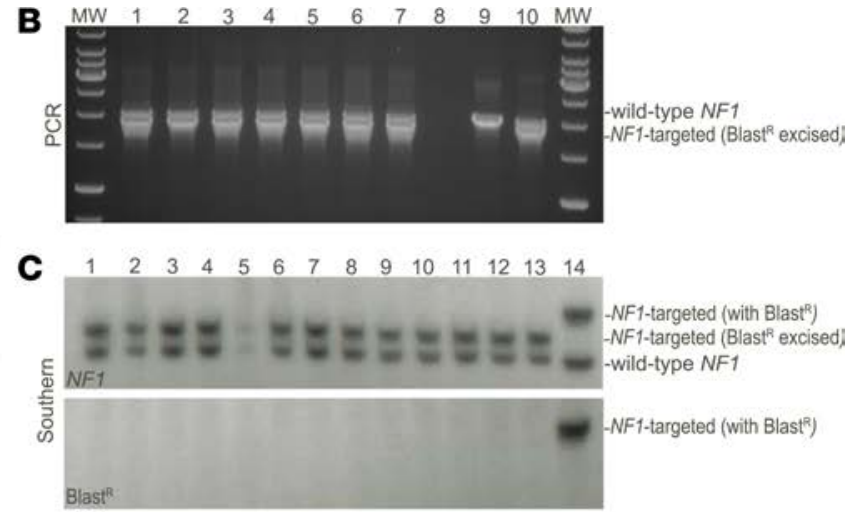
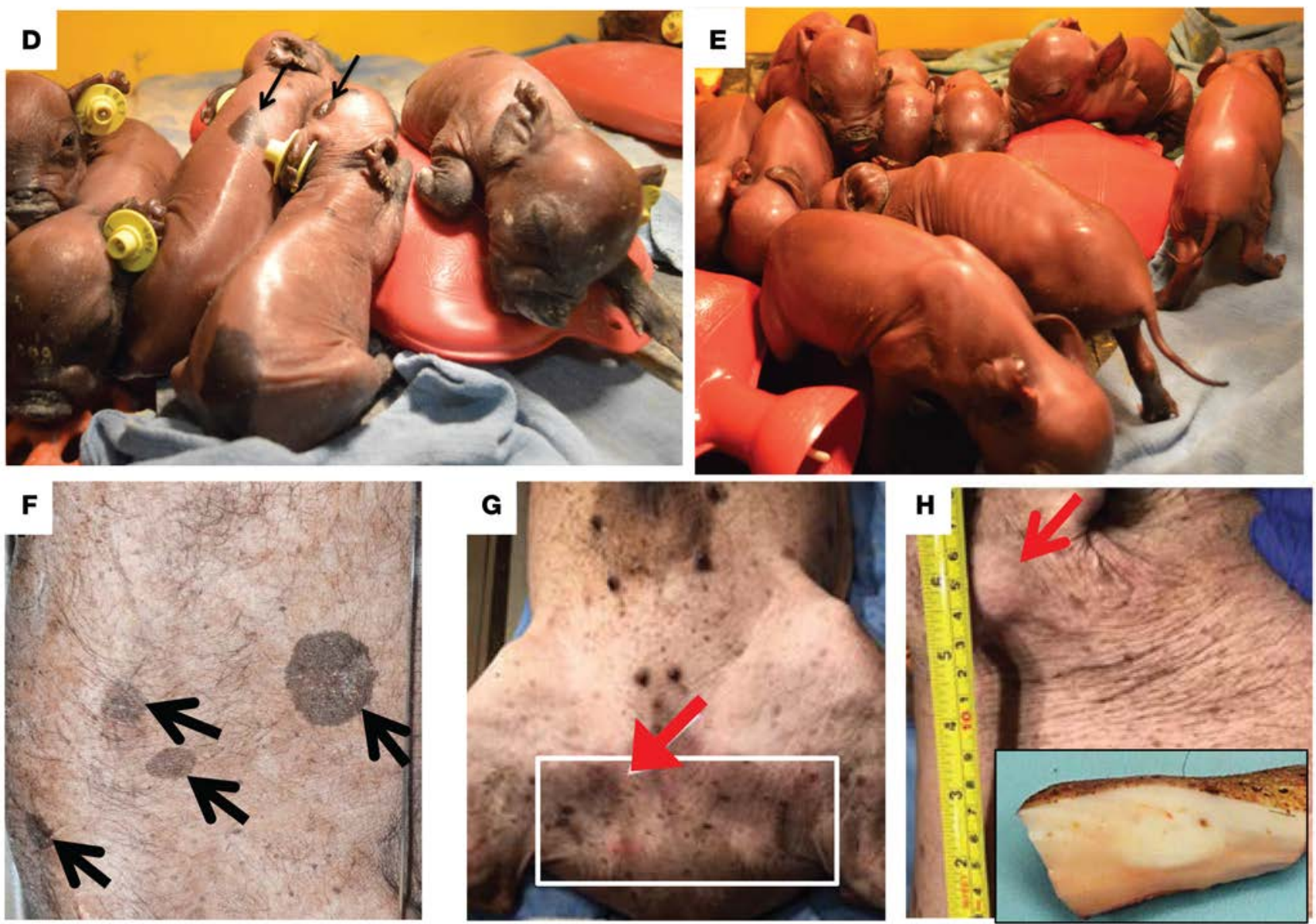

Figure 1. Generation of $\mathbf{N F}^{+/ e x 42 d e l}$-targeted miniswine. (A) Gene targeting scheme depicting the deletion of exon 42 . Exons $41-43$ are shown as gray boxes, and the Blast ${ }^{R}$ cassette is shown in red. Dotted vertical lines indicate the gene-targeting construct boundaries. Arrows indicate PCR primers. NF1 Southern blot probe is indicated by a black line and labeled "probe." Red arrowhead represents remaining loxP site. Figure is not to scale. (B) Representative PCR genotyping. Lanes 1-7 represent individual miniswine, lane 8 is a no-template control, lane 9 is an $N^{2} 1^{+/ e x 42 d e l}$ with Blast ${ }^{R}$ control, and lane 10 is an $N F 1^{+/ e x 42 d e l}$ Blast ${ }^{R}$-excised control. PCR primer locations are indicated in A. (C) Representative genomic Southern blot with NF1 (upper panel) and Blast ${ }^{R}$ (lower panel) probes. Ncol/EcoNi-digested DNA from WT NF1 miniswine yields a $3.0 \mathrm{~kb}$ product, whereas the same digest of $\mathrm{NF}^{+/ \text {ex42del }}$ Blast ${ }^{\mathrm{R}}$-excised yields a product

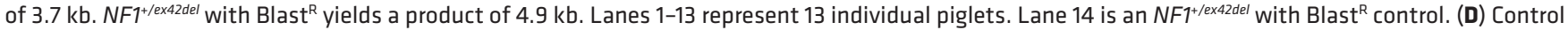
litter presents with no pigmentation. Characteristic café au lait macules (E and $\mathbf{F}$, back rump and head regions), auxiliary/inguinal freckling (G, flank), and cutaneous tumors (H, neck with cross-sectional insert) are evident on $\mathrm{NF}^{+/ / e x 42 d e l}$ miniswine.

pigmentation of the lower epidermis (e.g., basal layer; Figure 3, A and B). Epidermis in humans and swine normally has scattered, solitary, dark-colored (i.e., pigmented) cells near the basement membrane that are consistent with melanocytes (Figure 3B, red arrows). In NF1 mutant animals, the macules had increased incidence of heavily pigmented cells compared with adjacent normal skin (Figure 3, A-C). We also observed an 
A

\begin{tabular}{|c|c|c|c|}
\hline & $\begin{array}{l}\text { Café au Lait Spots } \\
\text { Present }\end{array}$ & $\begin{array}{l}\text { Tumor Lesion } \\
\text { Present }\end{array}$ & $\begin{array}{c}\text { Initial T-maze Learning } \\
\text { Deficit }\end{array}$ \\
\hline$N F 1^{* *}$ & $0 / 6$ & $0 / 6$ & $0 / 5$ \\
\hline$N F 1^{* / \Delta e x \Delta 2 d e l}$ & $18 / 18$ & $8 / 18$ & $3 / 7$ \\
\hline
\end{tabular}

Figure 2. Description of observed animal phenotypes between NF1 and control swine. Time course of observed tumor formation in $\mathrm{NF}^{+/ \text {exazdel }}$ miniswine versus lack of tumors in WT $(+/+)$ controls over the course of this study.

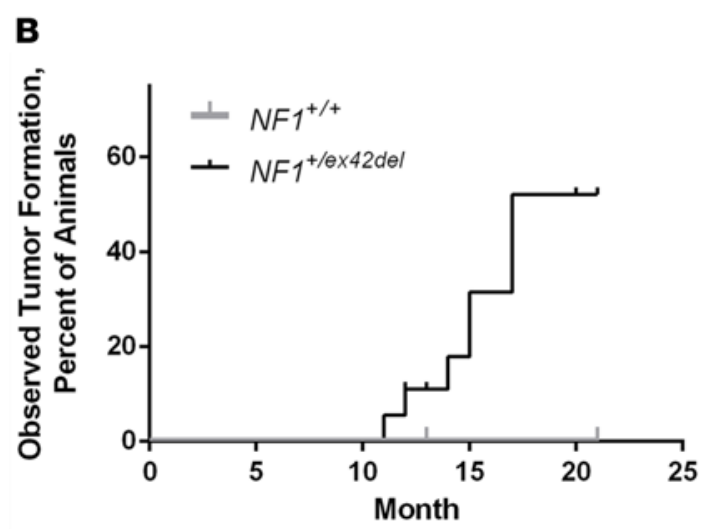

increased density of the neurovascular networks (i.e., the channels of nerves and vessels that course through the dermal collagen; Figure 3, A, B, and D, black arrows). Taken together, these results indicate that the targeted mutation in $N F 1^{+ \text {exx2del }}$ miniswine results in café au lait-like lesions immediately at birth.

NF1 mutation in swine cells results in elevated and sustained Ras activation. To confirm that our NF1 mutant model displayed perturbation in the Ras signaling pathway, swine fibroblasts were isolated from $3 \mathrm{WT}$ and $3 \mathrm{NF}^{+1}$ ex42del miniswine. Cells were cultured under basal (starved) and growth factor-stimulated (active) conditions, and Ras signaling was evaluated by Western blotting and IHC for various downstream Ras effectors. Each analysis demonstrated increased Ras activation and signaling in swine $N F 1^{+/ e x 42 d e l}$ cells compared with identically treated $N F 1^{+/+}$WT control cells (Figure 4). Western analyses showed elevated and sustained Erk1/2 phosphorylation by MAPK kinase (MEK) in stimulated $N F 1^{+/ \text {ext2del }}$ cells relative to controls(Figures $4, \mathrm{~A}$ and $\mathrm{B}$ ), which corresponded with reduced expression of neurofibromin protein in the $\mathrm{NF}^{+ \text {ext2del }}$ mutant cells (Figures 4, A and C). IHC staining for phospho-Erk1/2 was also performed in similarly starved and stimulated sets of cells, confirming increased levels of activated Erk1/2 in $N F 1^{+/ \text {ex42del }}$ cells (Figure 4D).

Another indicator of elevated Ras signaling is its induction of protective oncogene checkpoints via activation of the ARF-p53-p21 and p16INK4a-Rb tumor-suppressor pathways (38-40). Over time, there is strong selective pressure to inactivate those pathways, facilitating the Ras-mediated transformation that is observed in malignant NF1 tumors, such as MPNSTs. We first examined p53 activation by assessing its levels and induction of its transcriptional target, p21, in the same serum-stimulated WT and $N F 1^{+/ \text {ex } 42 d e l}$ cells using IHC (Figure 4E). Both p53 and p21 were significantly upregulated in $N F 1^{+/ \text {ex } 22 d e l}$ cells, reflecting heightened Ras signaling associated with NF1 deficiency. Likewise, Western blot analysis of serially passaged porcine cells revealed premature upregulation of p16INK4a in $N F 1^{+/ \text {ex42del }}$ cells, whereas WT cells displayed the typical pattern of p16INK4a induction with increasing passage (Figure 4F). Lastly, we examined expression of 7-in-absentia homologue (SIAH), an evolutionarily conserved E3 ubiquitin ligase whose expression is indicative of Ras pathway activation and is necessary for Ras-mediated cell transformation and tumorigenesis $(41,42)$. SIAH expression, essentially absent in normal WT controls, was selectively upregulated in $N F 1^{+/ \text {ex42del }}$ cells (Figure 4E). Together, these results provide important molecular validation

Table 1. Representation of the percent of $\mathbf{N F}^{+/ e x 42 d e l}$ miniswine with café au lait macules, cutaneous tumors, and learning deficits.

\begin{tabular}{lccc}
\hline & Café au Lait Spots Present & Tumor Lesion Present & Initial T-maze Learning Deficit \\
$+/+$ & $0 / 6$ & $0 / 6$ & $0 / 5$ \\
\hline $\mathrm{NF} 1+$ /ex42del & $18 / 18$ & $8 / 18$ & $3 / 7$
\end{tabular}


A

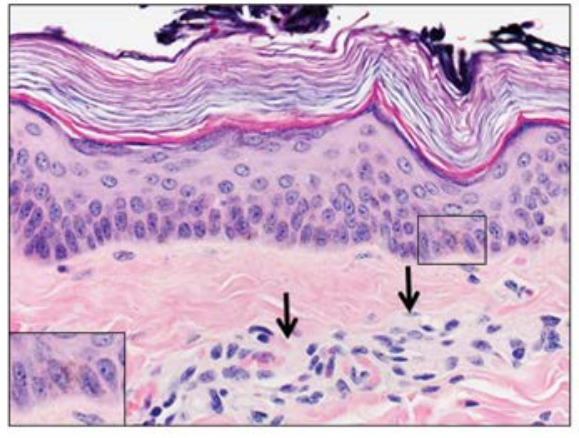

C

\section{Heavily-Pigmented Melanocytes}

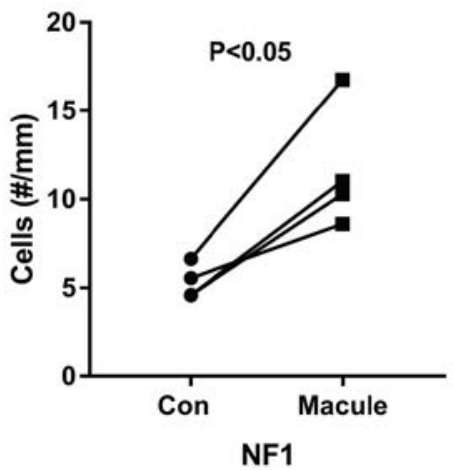

B

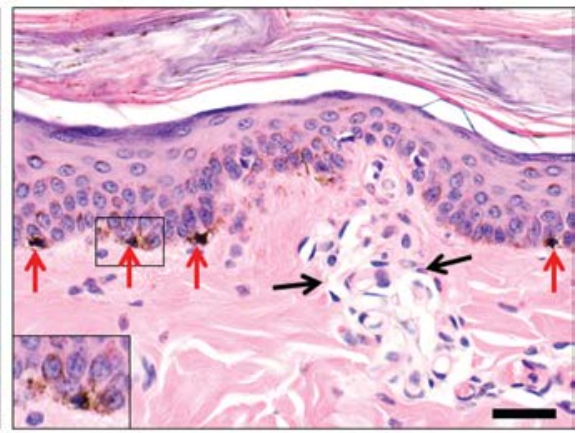

D

Neurovascular Networks

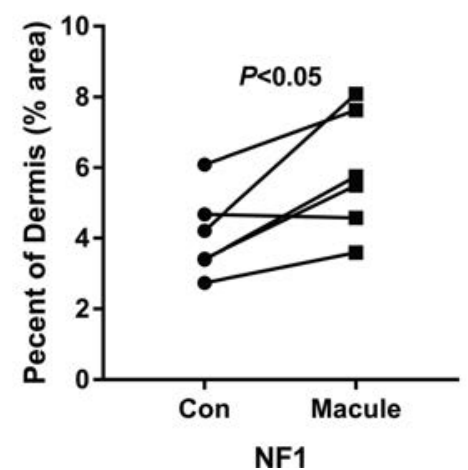

Figure 3. Presence of café au lait macules in newborn NF1 mutant miniswine. Histopathology of the macules from $\mathrm{NF}^{+/ \text {exa2del }}$ animals age newborn to $<4$ months showed increased melanin content within cells of the lower/ basal epidermis compared with adjacent control skin from NF1+/ex42del (insets), H\&E stains. Skin has scattered pigmented cells along the basal layer (A, black arrows) that are morphologically consistent with melanocytes. Heavily pigmented melanocytes (B, red arrows) were more easily detected in the basal epidermis of macules compared with adjacent skin in $\mathrm{NF}^{+/ / \text {ex } 42 d e l}$ miniswine $(P<0.05$, paired 2 -tailed Student's $t$ test) (C). Additionally, the dermis of macules compared with adjacent controls skin of $\mathrm{NF}^{+1}$ ex42del miniswine had increased expansion of neurovascular networks (black arrows, $\mathbf{A}$ and B) as a percent of dermis area $(P<0.05$, paired Student's $t$ test) (D). $n=4-6$; scale bar: $30 \mu \mathrm{m}$.

of the $N F 1^{+ \text {lext2del }}$ miniswine model by establishing elevated and sustained Ras signaling.

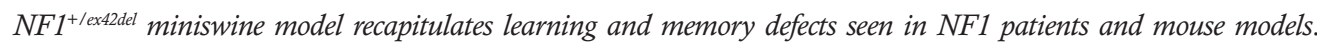
Learning and memory deficits are common in patients with NF1 (26). A T-maze test, similar to those used in rodent learning and memory analyses, was employed to examine this aspect in male $N F 1^{+ \text {ex } x 2 d e l}$ miniswine (Figure 5A). At 9-10 months of age, $N F 1^{+/ \text {ex } 42 d e l}$ miniswine showed a significantly lower percentage of accuracy in choosing the correct reward arm on day 1 of acquisition (Figure $5 \mathrm{~B}$ ). About $43 \%$ of $N F 1^{+/ \text {ex } 42 d e l}$ miniswine presented with a learning delay at this stage (Table 1). This difference was resolved on day 2 of acquisition and was not present during the reversal phase (Figure 5, B and C). These results are consistent with an initial learning delay seen in $\mathrm{NF}^{+/-}$mice and patients, which can be resolved with additional training (43).

Over the course of these studies, swine were observed on a daily basis, and several $N F 1^{+/ e x 42 d e l}$ animals appeared to have anxious, hyperactive tendencies when housed in their pens. Such behaviors are typical in patients with NF1 and certain mouse models of the disease $(44,45)$. To quantify this behavior in the miniswine, an unfamiliar-object exploration task was performed over a 2-day period. On day $1, N F 1^{+ \text {ex } 42 d e l}$ animals took significantly longer to initially touch the object in the pen, though they spent the same amount of time with the object as their control counterparts (Supplemental Figure 1A; supplemental material available online with this article; https://doi.org/10.1172/jci.insight.120402DS1). This difference was resolved on day 2 and did not present itself with the second object placed in the pen (Supplemental Figure 1B). Together, these initial learning and social delays indicate that our model recapitulates several key behavioral deficits of the disease previously seen in NF1 patients and mouse models.

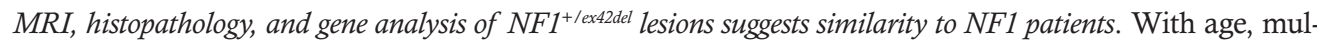
tiple $N F 1^{+ \text {exx2del }}$ — but not WT miniswine - developed cutaneous tumors consistent with neurofibromas within the scope of NF1 tumors seen in humans. MRI was used to capture in vivo data for suspected tumors in $3 N F 1^{+/ \text {ex42del }}$ miniswine, between the ages of 11 and 17 months of age (Figure $1 \mathrm{H}$, Figure 6, and Supplemental Figure 2). The lesions ranged in number from 1-4 per animal and were located on the neck and/or flank of the animals (Figure 6, A and B). Lesions were large, varying in size from $43 \times 37 \mathrm{~mm}$ up to $160 \times 48$ $\mathrm{mm}$. The lesions demonstrated heterogeneous enhancement on T2-weighted MRI with 1 lesion displaying a central hypointensity (Figure 6, C and D) and was iso-intense to muscle on T1-weighted MRI. All lesions 
A

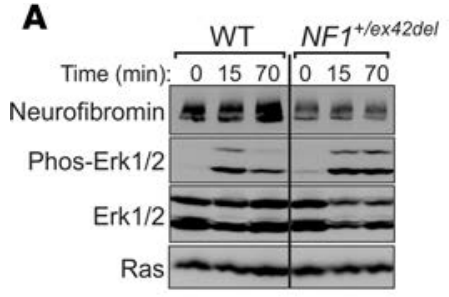

B

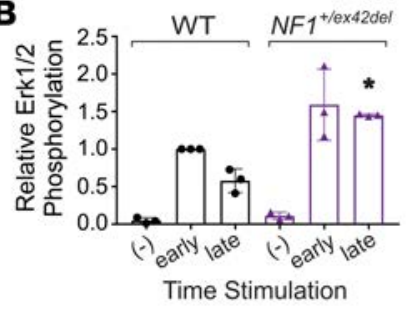

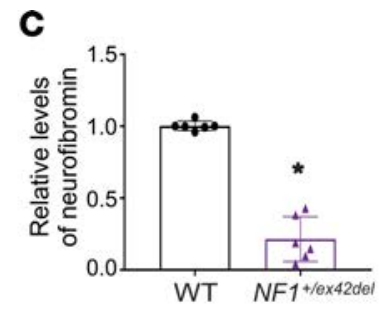
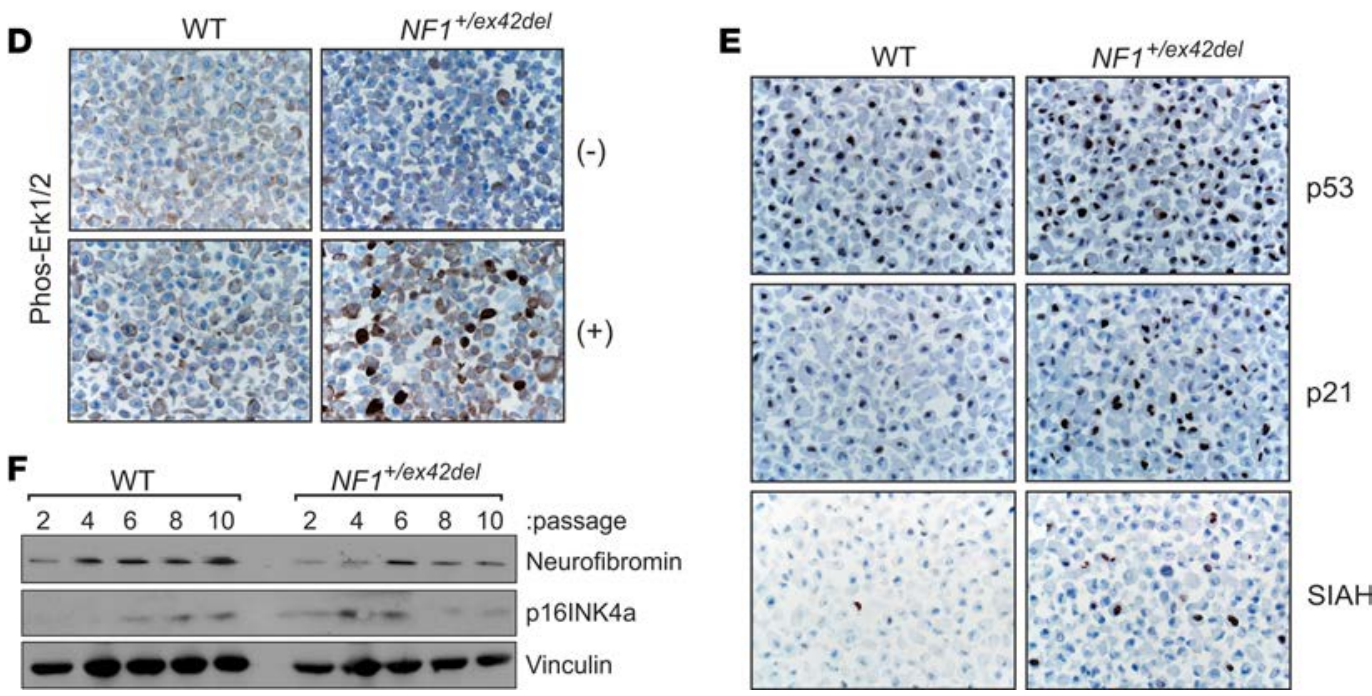

Figure 4. Increased Ras activation in swine $\mathbf{N F}^{+/ \text {ex42del }}$ mutant cells. (A) Western blot analyses of extracts from WT and mutant $N F 1^{+/ e x 42 d e l}$ swine fibroblasts that were growth factor stimulated for 0,15 , or 70 minutes and probed with antibodies to neurofibromin, phosphorylated Erk1/2 (Thr202/Tyr204), total Erk1/2, and total Ras. Data are representative of $n=3$ experiments using cells isolated from 2 WT and 2 NF1+ex4zdel miniswine. (B) Graph of Western blot data from $n=3$ experiments showing increased and sustained Erk1/2 phosphorylation levels in NF1+ex42del cells compared with WT counterparts at the same time points ( ${ }^{*} P<0.05$, paired Student's $t$ test). Cells were unstimulated (-) or growth factor stimulated for 15 minutes (early) or 60-90 minutes (late). Phosphorylated Erk1/2 levels were quantified by ImageJ and normalized to total Erk1/2 expression with error bars representing the mean \pm SD. (C) Quantification of neurofibromin levels in WT versus $N F 7^{+/ \text {ex42del }}$ cell lysates from $n=6$ independent experiments using separately isolated cells from 3 WT and $3 N F 1^{+/ \text {ex42del }}$ miniswine, as measured by Image) relative to loading control. Data represent the mean $\pm S D\left({ }^{*} P<0.05\right.$, paired Student's $t$ test). (D) IHC stains (representa-

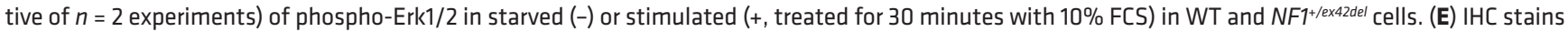
showing increased p53, p21, and SIAH protein levels in growth factor stimulated NF+1/ex42del cells compared with WT controls. Data in $\mathbf{E}$ are representative of $n=3$ experiments, each performed using separately isolated cells from 3 WT and $3 N F 7^{+/ e x 42 d e l}$ animals. Images for $\mathbf{D}$ and $\mathbf{E}$ taken at $400 \times$ magnification. (F)

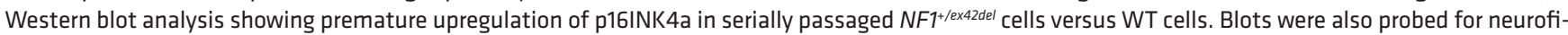
bromin and vinculin (loading control) levels. Data are representative of $n=3$ experiments using cells isolated from $3 \mathrm{WT}$ and $3 \mathrm{NF}{ }^{+/ \text {ex } 42 d e l}$ miniswine.

showed minimal contrast enhancement in the postcontrast spoiled 3-D gradient echo (LAVA) sequence.

Three $N F 1^{+/ \text {exz2del }}$ miniswine were selected for brain imaging from the behavioral testing cohort; 1 with no learning deficit and 2 with the largest learning deficit. In the cerebellum of the animal with the largest behavioral deficit, a $17 \times 6 \mathrm{~mm}$ region of hyperintensity was evident on the fluid attenuation inversion recovery (FLAIR) sequence and T2-weighted MRI data (Figure 6, E-L, yellow arrows). The lesion was not evident on T1-weighted MRI. This finding is in accordance with those of Piscitelli et al., who reported cerebellar T2 hyperintensities associated with lower intelligence quotient (IQ) than those without in human NF1 patients $(46,47)$. Lesion abnormalities were not detected in the other 2 miniswine. Hyperintense regions seen on T2-weighted MRI brain scans in NF1 are reported to occur in $40 \%-70 \%$ of NF1 subjects; however, the histological basis for this finding remains unclear (48-50). An NF1 animal model presenting with these "unidentified bright object" brain findings provide a unique opportunity for further investigation and understanding.

Imaging characteristics were similar to those reported for superficial plexiform neurofibromas in human NF1 patients (47), although the size of the lesions in the miniswine were larger than human superficial neurofibromas. Histopathology of biopsied tumors from $\mathrm{NF}^{+/ \text {exx2del }}$ miniswine showed multiple, low cellularity, $\mathrm{S}_{100^{+}}$neurofibromas (Figure 7, A-E). We further assessed the neurofibromas from this $N F 1^{+/ \text {ex } 22 d e l}$ miniswine and found $\mathrm{vWF}^{+}$staining of endothelial cells (Supplemental Figure 3, A-C) and aggregates of eosinophils and mast cells within the neurofibroma tissues (Supplemental Figure 4, A-D). Additionally, as somatic mutation of the remaining allele - such as loss of NF1 heterozygosity ( $\mathrm{LOH})$ - is thought to be an important 
A

$$
15^{\prime}
$$

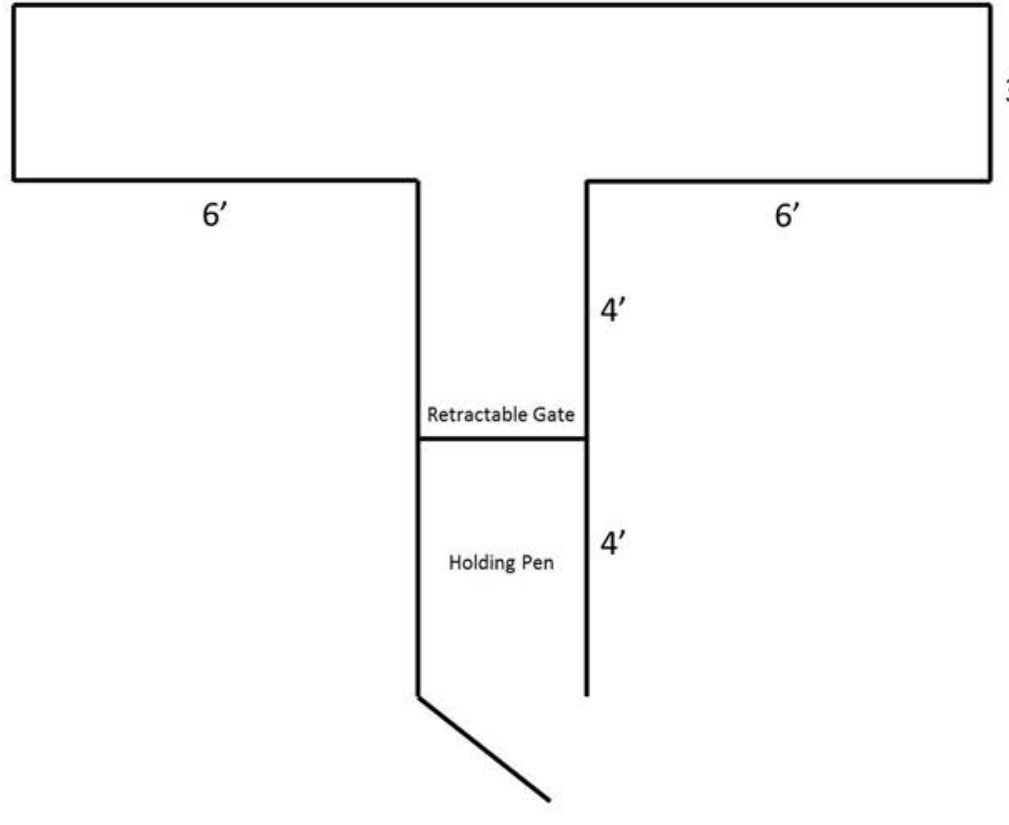

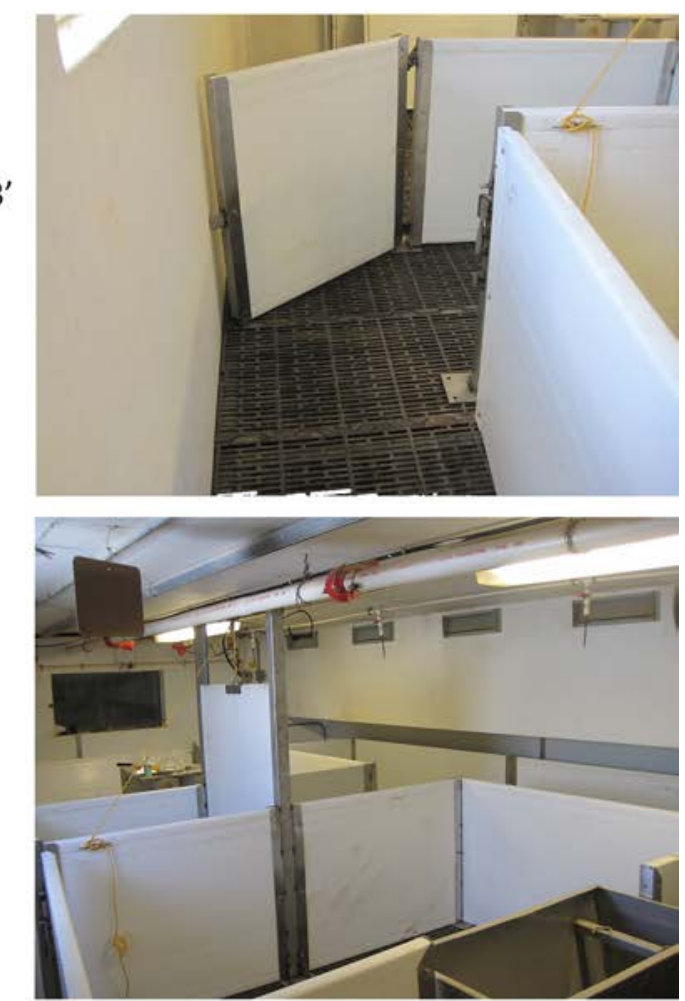

C

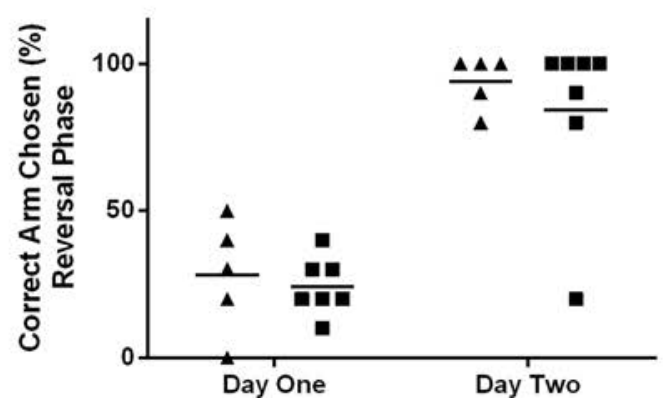

$\Delta$ Control

- $N F 1^{+/ e x 42 d e l}$

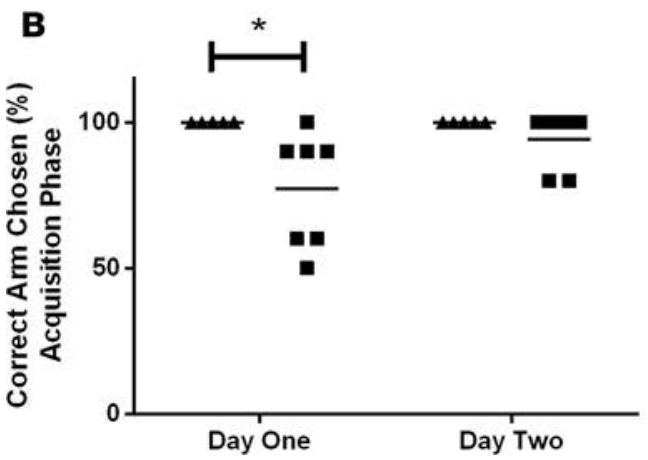

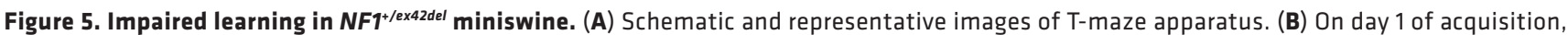
$N F 7^{+/ e x 42 d e l}$ miniswine had a significantly lower percent accuracy of choosing the correct arm compared with controls. (C) This difference was resolved on day 2 of acquisition and was not present during the. Mean shown, 2-tailed Mann-Whitney $U$ test. $n=5-7$. ${ }^{*} P<0.05$.

step in neurofibroma development, we preliminariily explored whether cultured $N F 1^{+/ \text {exz2del }}$ miniswine tumor cells support a second-hit hypothesis (51). Of the 2 tumor samples from 2 animals analyzed by reverse transcription PCR (RT-PCR) spanning the region of the germline deletion, 1 sample had relatively less WT NF1 transcript at the germline level (Figure 7F). While this reduction in transcript may be caused by mutations other than $\mathrm{LOH}$, these initial results support a second-hit hypothesis in $N F 1^{+/ \text {ext2del }}$ miniswine tumor lesions. A more in-depth analysis of somatic mutations will be pursued in future studies.

Calcium and sodium channel dysregulation in NF1 mutant swine sensory neurons. We and others previously reported an increase in voltage-gated $\mathrm{N}$-type $\mathrm{Ca}^{2+}(\mathrm{CaV} 2.2)$ channel current densities in neurons from $\mathrm{Nfl}^{+/-}$mice, placing CaV2.2 as the major contributor to whole cell $\mathrm{Ca}^{2+}$ currents in NF1, with no significant differences in L-, P/Q-, T-, and R-type currents $(52,53)$. Therefore, to demonstrate that similar calcium channel changes occurred in NF1 miniswine model, dorsal root ganglion (DRG) neurons isolated from WT and mutant $\mathrm{NF1}^{+ \text {lext2del }}$ were examined for their ability to flux calcium. $\mathrm{Ca}^{2+}$ influx was evoked by a 15-second application of a 90-mM KCl solution, a concentration known to recruit mostly Cav2.2 channels. DRGs from mutant $N F 1^{+ \text {exxa2del }}$ miniswine had significantly higher amounts of peak calcium in response to the depolarizing stimulus when compared with DRGs from WT miniswine (Figure 8, A and B). 

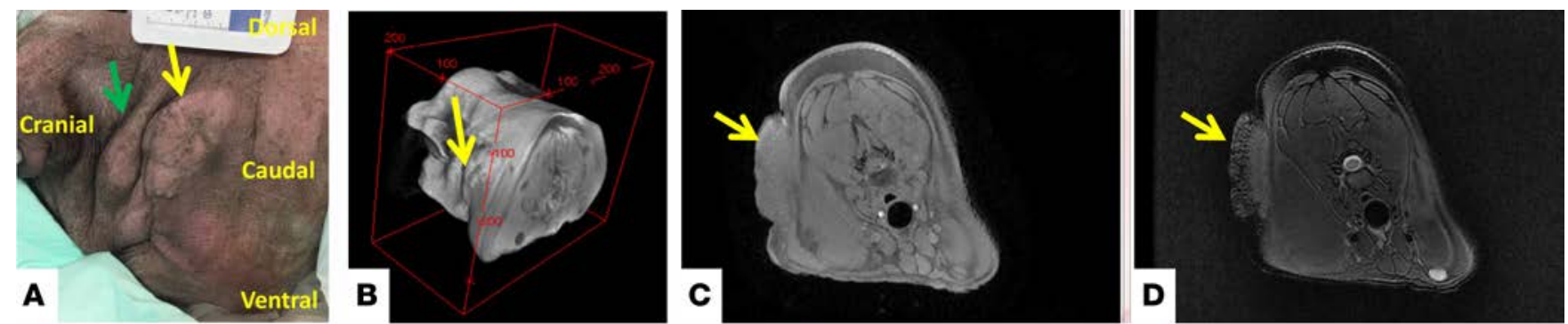

E
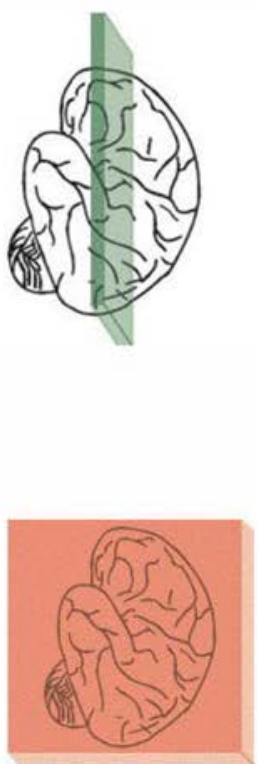

I
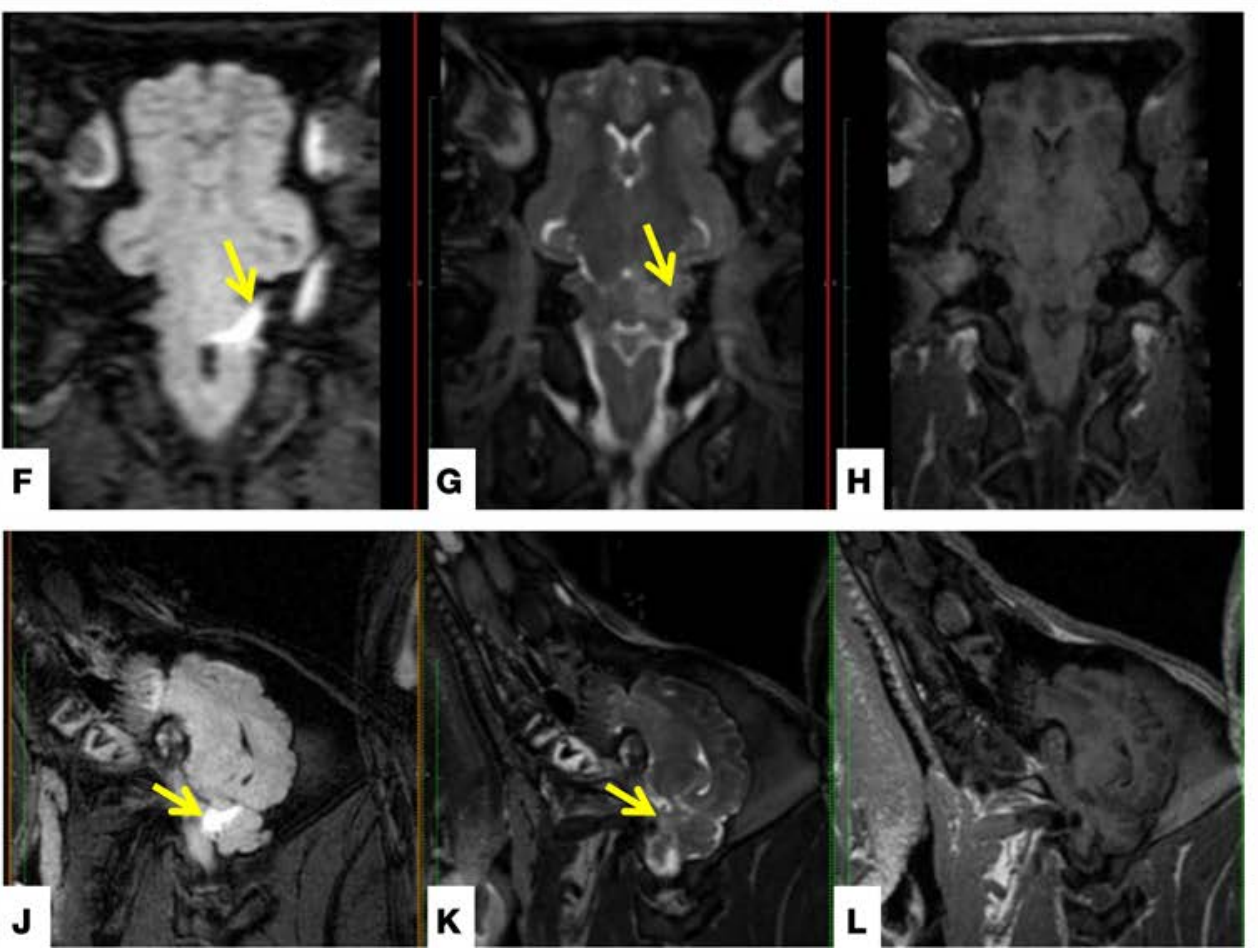

Figure 6. Imaging of classic neurofibroma and early indication of CNS-tumor formation in $\mathbf{N F}^{+/ / e x 42 d e l}$ miniswine model. Neurofibromas on the neck of an 11-month-old male NF1+/ex42del mutant miniswine (green and yellow indicate separate lesions) (A) and a volumetric reconstruction from the MRI data (B). The lesion (yellow arrow) is iso-intense to muscle on T1-weighted MRI (axial view; C) and demonstrates a central hypo-intense region on T2 weighted MRI (axial view; D) and minimal contrast enhancement (data not shown). An 11-month-old male NF1 mutant with poor cognitive scoring through behavioral testing had a radiological finding in the brain. The axial orientation (E-H) and corresponding sagittal view (I-L) are shown. A cerebellar region of hyper-intensity is evident on a fluid attenuation inversion recovery (FLAIR) MRI (F and J) (highlighted by yellow arrow). This finding was less evident on T2-weighted MRI without fluid suppression (G and K), and it was not evident on T1-weighted MRI (H and L).

$\mathrm{Na}^{+}$peak current densities are increased in sensory neurons from $\mathrm{NfI}^{+/-}$mice (54). We recently reported that rat sensory neurons transfected with a CRISPR/Cas9 plasmid containing Nf1 single-guide RNA (sgRNA) demonstrated increases in total and tetrodotoxin-sensitive (TTX-sensitive), but not TTX-resistant, voltagegated $\mathrm{Na}^{+}$channel current densities (53) upon their isolation with a combined electrophysiology and pharmacological protocol $(53,55)$. Here, we set out to authenticate if sodium channel dysregulation could also be recapitulated in DRGs from mutant $N F 1^{+/ \text {ext2del }}$ miniswine. Large sodium currents were observed in miniswine DRGs (Figure 8C). Consistent with rodent data $(54,56,57)$, we observed a significant increase in the current densities (peak current amplitudes normalized by the cell capacitance) in mutant $N F 1^{+/ e x 42 d e l}$ miniswine when compared with DRGs from counterparts (Figure 8D). Together, these data confirm dysregulation of calcium and sodium channels in $N F 1^{+ \text {exa2del }}$ animals and suggest a role of swine neurofibromin in calcium and sodium channel regulation, similar to what has been reported in mice $(29,58,59)$.

\section{Discussion}

This study describes the first genetically engineered large animal model of NF1 and shows that it faithfully recapitulates the molecular and phenotypic hallmarks of the human disease. $N F 1^{+/ e x 42 d e l}$ animals presented 

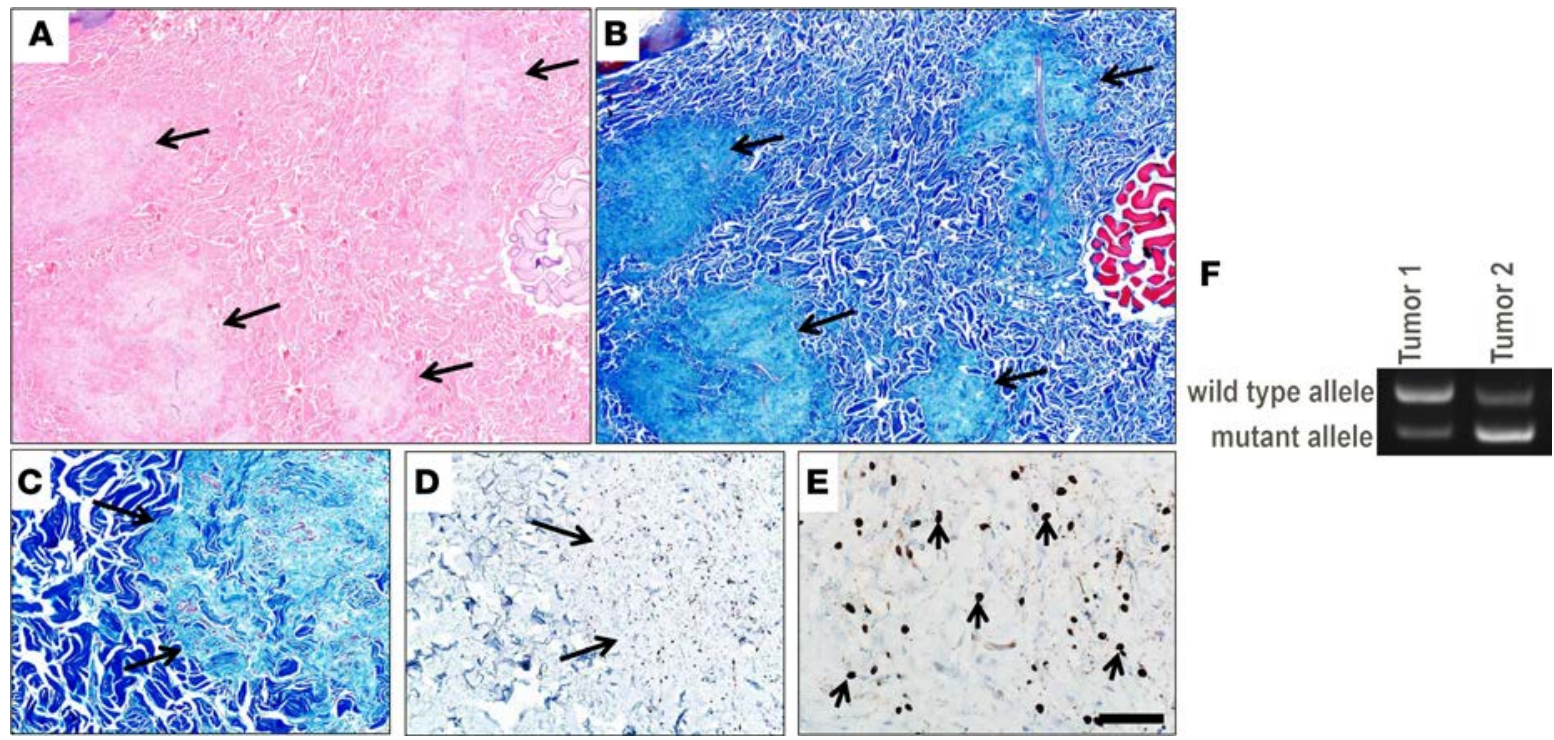

Figure 7. Histopathological examination of biopsy tissue from a $\mathbf{N F}^{+/ e x 42 d e l}$ miniswine with neurofibromas. Serial sections of a dermal mass showing multifocal neurofibromas (arrows) that efface the normal dermal collagen ( $\mathbf{A}$ and $\mathbf{B}$ ). While the multifocal tumors are seen using both stains, the Masson's trichrome stain may be more useful in this specific case for seeing the changes. Serial sections (C and $\mathbf{D})$ of the interface between the neurofibroma (arrows) and normal dermis (C and D). Higher magnification shows the scattered S100+ immunostaining (arrows) within the neurofibroma (E). H\&E stain (A), Masson's trichrome stain (B and C), and S100 IHC with hematoxylin counterstain (D and E). Scale bar: $600 \mu \mathrm{m}$ (A and B), $185 \mu \mathrm{m}$ (C and D) or $45 \mu \mathrm{m}$ (E), respectively. A-E are representative of 6 total tumors analyzed from 2 animals. (F) NF1 RT-PCR of 2 tumor samples from 2 NF1+ex42del animals. One tumor sample shows relative loss of NF1 WT RNA transcript at the germline level.

with café au lait macules and neurofibromas, 2 classic disease phenotypes that are lacking in heterozygous Nf1 rodent models $(14,15)$ (reviewed in ref. 58). In terms of tumor classification, diffuse cutaneous neurofibromas (DCNs) are a subtype of neurofibroma that often arises in children to young adults in the neck/ head region as raised, plaque-like tumors. In contrast to other neurofibromas, the $\mathrm{S} 100^{+} \mathrm{Schwann}$ cells of DCNs have a more rounded morphology and are typically scattered on a low-cellularity, collagenous matrix that contains other cell types such as fibroblasts (59). The clinical and pathological features of DCNs in humans parallel the early tumor phenotypes observed in the $N F 1^{+/ \text {ex42del }}$ miniswine. Furthermore, MRI of tumor growths in the neck of multiple animals suggest similarities to human plexiform neurofibromas, with lesions presenting as iso-intense on T1-weighted MRI with hypointense central regions on T2-weighted MRI (60). Whether these putative plexiform neurofibromas represent progression of the DCNs or possibly additional neurofibroma subtypes remains to be studied as these tissues are harvested.

While neurofibromas are benign, complications can arise due to location, size, organ compression, pain, and/or malignant transformation $(9,11,12)$. Indeed, about one-third of the larger plexiform neurofibromas transform into MPNSTs, and the field is currently in desperate need of strategies for early MPNST detection (61). Due to the prevalence of indolent tumors in NF1, routine screening with medical imaging for nonsymptomatic patients is not recommended (62). However, medical imaging plays a key role in the clinical management of symptomatic NF1 patients in the assessment of tumor location and treatment interventions (63). In addition, imaging has a significant role in assessing treatment response in clinical trials $(64,65)$. To date, none of the $N F 1^{+ \text {/ext2del }}$ animals have developed MPNSTs, although this was not unexpected since the animals are fairly young and MPNSTs arise in only $10 \%-15 \%$ of NF1 patients (11-13). We anticipate that MPNSTs will develop spontaneously in a similar percentage of $N F 1^{+/ \text {ext2del }}$ animals as the herd is expanded and that they can be induced by CRISPR/Cas9 editing, as recently performed in mice (25). The advantage of the NF1 porcine model is that animals reach a similar size as adult humans and can be imaged on clinical CT and MRI instruments (36). Consequently, this model provides a powerful platform to develop new early imaging detection strategies for NF1 tumors and, at the very least, provide a longitudinal assessment of neurofibroma dynamics.

The $N F 1^{+/ \text {ex42del }}$ miniswine also presented with behavioral abnormalities. These included an initial learning delay in the T-maze task, an initial hesitance to interact with an unfamiliar object, and overall observations of hyperactivity and anxiety while the animals were housed. This is consistent with behavioral and cognitive alterations seen in mouse models of NF1, as well as the human disease, where $35 \%-50 \%$ of 

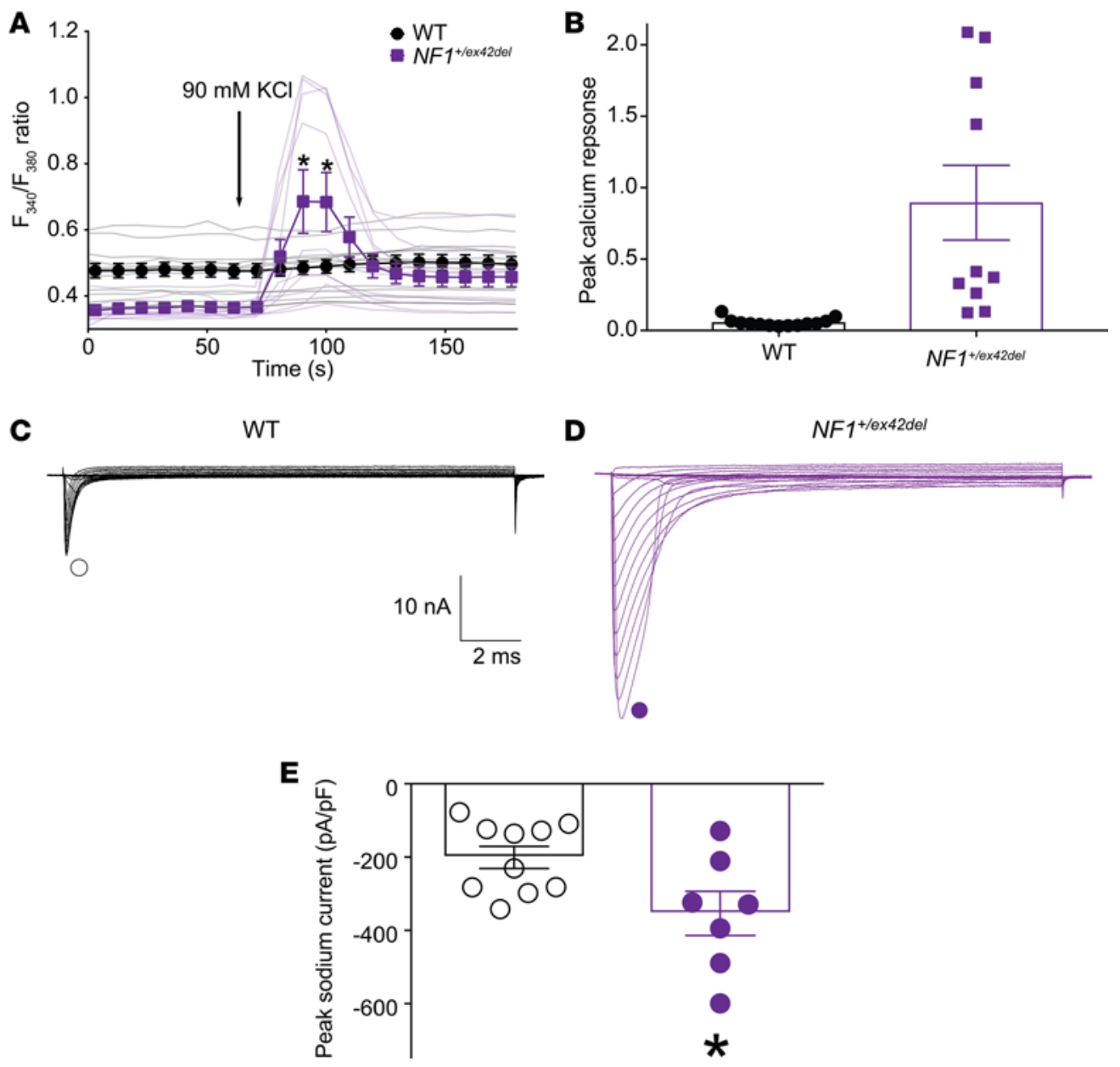

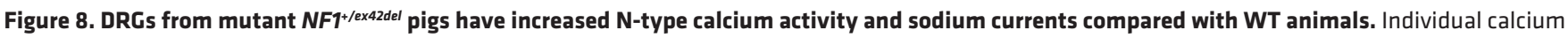
responses and summary data of DRG neurons challenged with 90 potassium chloride [ $n=13$ for WT (4-month old female pig) and $n=10$ for $N F 1^{+/ e x 42 d e l}$ (4-month old male swine)] (A). Peak calcium responses are plotted in B. Asterisks indicate statistical significance compared with untreated cells $\left({ }^{*} P<\right.$ 0.05 , Two-tailed Student's $t$ test analyses). Representative family of total $\mathrm{Na}+$ current traces are illustrated for sensory neurons from WT or $N F 7^{+/ e x 42 d e l}$ swine (C). Peak current densities for the indicated conditions (D). Numbers of cells: [( $n=13$ for WT (4-month old female swine) and $n=10$ for $N F 7^{+/ e x 42 d e l}$ (4-month old male swine)]. Asterisk denotes statistical significance compared with WT cells (Mean $\pm \mathrm{SEM},{ }^{*} P<0.05$, Unpaired 2-tailed Student's $t$ test). Experiment was performed with experimenter blinded to the genotype.

NF1 patients present with cognitive impairment and NF1 children display attention and social competence deficits $(10,66,67)$. Over the last decade, studies in Nf1-deficient mice have implicated neurofibromin in regulating the release of the inhibitory neurotransmitter GABA in the hippocampus and frontal lobe, which controls spatial and executive working memory $(26,27,68)$. This suggests that mutations in $N f 1$ lead to learning deficits through perturbed ERK signaling, GABA release, and consequent changes in LTP (68). Studies are ongoing to determine if a similar pathway mediates the behavior deficits noted in the $N F 1^{+/ \text {ex } 42 d e l}$ miniswine model and to additionally evaluate attention and social competencies.

At the molecular level, increased Ras activity is a defining feature of NF1 inactivation and of central importance to tumorigenesis in NF1 disease $(69,70)$. Our molecular analyses of fibroblasts from $\mathrm{NF1}^{+1}$ ex42del miniswine verified reduced neurofibromin expression and elevated Ras/MAPK signaling in those cells compared with NF1 WT controls. Specifically, we observed heightened activation of key downstream effectors of Ras in NF1 heterozygous cells. NF1 mutant cells showed increased phosphorylation of Erk1/2 by MEK and selective upregulation of SIAH, an E3 ubiquitin ligase whose expression marks Ras pathway activation and is required for Ras-mediated cellular transformation and tumorigenesis $(41,42)$. The biological relevance of finding heightened MEK activity in NF1-deficient cells is illustrated by the remarkable therapeutic success of the MEK inhibitor, selumetinib, in halting disease progression in children with NF1 disease who have inoperable plexiform neurofibromas (71). 
Consistent with Ras activation, analyses of porcine fibroblasts also established increased expression of the checkpoint regulators, p16INK4a and p53, and the p53 transcriptional target, p21. In normal cells, those factors are upregulated by hyperactive Ras as part of an oncogene checkpoint response designed to remove aberrantly proliferating cells from an organism before they become transformed and tumorigenic $(39,40)$. The small fraction of cells that escape checkpoint inhibition do so by eliminating the checkpoint regulators, thereby enabling cellular transformation and malignant tumor development. The fact that porcine $\mathrm{NF1}^{+/ \text {ex42del }}$ cells display premature $\mathrm{p} 16 \mathrm{INK} 4 \mathrm{a}$ and $\mathrm{p} 53 / \mathrm{p} 21$ upregulation strongly suggests that selective pressure will eventually induce their loss and promote consequent cancer formation in these NF1 mutant animals. Indeed, continued passaging of $N F 1^{+/ \text {ex42del }}$ cells caused progressive loss of p16INK4a expression. We suggest that tumors arising in NF1 mutant miniswine will provide a remarkable resource for crossspecies (human, mouse, and pig) comparisons of tumor profiles at the genomic, epigenetic, proteomic, and metabolomic levels, facilitating the identification of key alterations driving NF1 tumorigenesis.

Swine DRGs were also isolated from $N F 1^{+/ \text {ext2del }}$ animals and shown to have dysregulated calcium and sodium channels. While the pathophysiology of chronic pain and migraine are not completely understood, extensive clinical evidence supports a cardinal role for calcitonin gene-related peptide (CGRP) in these disorders, a peptide critical to peripheral inflammation and central and peripheral nociception (72). Haploid insufficiency of neurofibromin in mice has previously shown increases in CGRP release (73) and enhanced nociceptor excitability (54). We and others reported that sensory neurons from $\mathrm{Nf1}^{+/-}$mice exhibit increased $\mathrm{N}$-type voltage-gated $\mathrm{Ca}^{2+}(\mathrm{CaV} 2.2)$ currents that likely account for the increased release of neuropeptides that occurs in $\mathrm{Nf}^{+/-}$sensory neurons $(52,74)$. Our data showing dysregulation of calcium and sodium channels are in agreement with those reported in mice and rats, and thus, they functionally validate miniswine DRGs as a potentially new model of NF1. Collectively, these peripheral adaptations are likely to increase sensory neuron excitability and release of excitatory transmitters to the spinal dorsal horn to establish and maintain a state of central sensitization. Whether these adaptations will result in altered pain thresholds or sensitivities in swine is the subject of ongoing studies in our laboratories.

In summary, we present a potentially novel porcine model of NF1 that shows many hallmarks of the human disease, including skin pigmentation anomalies, tumor growth, altered pain signaling, and behavioral deficits. It is the first NF1 heterozygous animal to our knowledge that comprehensively develops these classic features of NF1, likely reflecting the intrinsic similarities between miniswine and humans with regard to their genetics, anatomy, and physiology. As such, this model provides unparalleled opportunities for advancing diagnostic medical imaging, biomarker discovery and characterization, and preclinical testing of therapeutics for treating NF1-associated cognitive deficits, pain, and tumorigenesis.

\section{Methods}

\section{Cloning swine NF1 genomic DNA sequence}

Targeting Vector Construction. Genomic DNA was isolated from Yucatan miniswine fetal fibroblasts. A 10.1$\mathrm{kb}$ PCR product that included a region from NF1 exon 41 to exon 48 was amplified using a high fidelity polymerase (Platinum Taq High Fidelity, Invitrogen) and NF1 primers pNF1-1F and pNF1-4R (Supplemental Table 1). The PCR product was subcloned into pCR2.1-TOPO (Invitrogen) and sequenced. All DNA sequencing was performed by the University of Iowa DNA Facility. This resulting plasmid served as the template for PCR amplification of the 5' and 3' homologous targeting arms, which were subcloned sequentially into a plasmid containing a PGK-Blast ${ }^{\mathrm{R}}$ cassette. The primers for the $5^{\prime}$ arm were $\mathrm{pNF} 1 \mathrm{XhoI}$ armF28 and pNF1SbfI5armR29. The primers for the $3^{\prime}$ arm were pNF1SbfI3armF31 and pNF1Hind3armR33. The

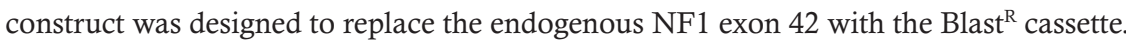

$r A A V$ production. PCR amplification of a $4.5-\mathrm{kb}$ amplicon from the plasmid described above was achieved by using the following primers: $\mathrm{pNF} 1 \mathrm{Not} 47 \mathrm{~F}$ and $\mathrm{pNF} 1 \mathrm{Not} 46 \mathrm{R}$. This product was subcloned into the rAAV proviral plasmid, pFBAAV2-CMVP.NpA (obtained from University of Iowa Gene Transfer Vector Core) and grown in Sure2 cells (Stratagene). The rAAV was produced by the University of Iowa Viral Vector Core Facility.

Fetal fibroblast infection and selection. Passage zero male Yucatan fetal fibroblasts $\left(1.0 \times 10^{6}\right)$ were infected with rAAV carrying the NF1 targeting construct. After 24 hours, cells were detached with trypsin and plated on forty-eight 96 -well collagen-coated plates. Selection was initiated 48 hours later with blasticidin (3 $\mu \mathrm{g} / \mathrm{ml}$ ). Ten to 13 days later, each infected cell plate was split among three 96 -well plates (1 plate for freezing, 1 for propagation, and 1 for immediate PCR screening). 
PCR screen and cell handling. Approximately $40 \%$ of wells contained live cell colonies following selection. Cells in the 96-well PCR plate were subjected to $5 \mu$ lysis buffer ( $50 \mathrm{mM} \mathrm{KCl}$ [Sigma], $1.5 \mathrm{mM} \mathrm{MgCl}$ [Sigma], $10 \mathrm{mM}$ Tris-Cl [RPI Corp], pH 8.5, 0.5\% Nonidet P40 [Amresco], 0.5\% Tween [RPI Corp], $400 \mu \mathrm{g} / \mathrm{ml}$ Proteinase K [Qiagen]) (75). Cell lysis plates were incubated at $65^{\circ} \mathrm{C}$ for 30 minutes, followed by $95^{\circ} \mathrm{C}$ for 10 minutes. Primers Screen F (NeoR), pNF1seq26F, LDLR 5F, and LDLR-Exon5R1 were used to PCR amplify $2 \mu \mathrm{l}$ of lysate with the following conditions: 2 minutes at $94^{\circ} \mathrm{C}, 30$ cycles of $94^{\circ} \mathrm{C}$ for 20 seconds, $66^{\circ} \mathrm{C}$ for 20 seconds, and $68^{\circ} \mathrm{C}$ for 4.5 minutes, and finally $68^{\circ} \mathrm{C}$ for 3 minutes. The expected product for the targeted allele was a $1.9-\mathrm{kb}$ and a $4.3-\mathrm{kb}$ product from the LDLR internal control gene. The PCR-positive cells were grown to $100 \%$ confluence and either infected with rAAV-Cre or expanded for the purpose of DNA isolation.

Excision of the Blast ${ }^{R}$ cassette. PCR-positive fetal fibroblast cells were infected with rAAV-CMV-Cre. Three to 6 days later, $90 \%$ of the infected cells were frozen, and the remaining cells were propagated for PCR characterization. Cells were lysed in $5 \mu 1$ lysis buffer. Excision of the selectable marker was detected by PCR using primers pNF1seq26F and pNF1Screen50R with the following conditions: 2 minutes at $95^{\circ} \mathrm{C}$, 28 cycles of $94^{\circ} \mathrm{C}$ for 20 seconds, $60^{\circ} \mathrm{C}$ for 20 seconds, $68^{\circ} \mathrm{C}$ for 3.5 minutes, and finally $68^{\circ} \mathrm{C}$ for 7 minutes.

Southern blot. To validate PCR-positive cell lines, genomic DNA was isolated (Gentra, Qiagen) from fibroblasts grown on the propagation culture dishes. Two to $10 \mathrm{ng}$ of genomic DNA was whole genome amplified (Repli-G, Qiagen) and digested with NcoI and EcoNI. Following gel electrophoresis, samples were transferred to a positively charged nylon membrane (Roche Diagnostics) by using an alkaline transfer procedure. The membrane was briefly rinsed in 5× SSC, completely dried, and subjected to UV crosslinking. The DNA probes for NF1 and Blast ${ }^{R}$ were produced by PCR amplification using the following primers: pNF1probe52F/pNF1probe53R and BlastCD-F/BlastCD-R, respectively. Probes were labeled with $\alpha-{ }^{32} \mathrm{P}$ by random priming using Prime-a-Gene Labeling System (Promega), and the radioactive probes were purified using CHROMA SPIN+TE-100 columns (Clontech). Membranes were prehybridized in Rapid-hyb Buffer (GE Healthcare) for 30 minutes at $65^{\circ} \mathrm{C}$; then, $25 \mu$ of $\alpha-{ }^{32} \mathrm{P}-$ labeled probe was added and hybridization proceeded at $65^{\circ} \mathrm{C}$ for 2 hours. The membrane was washed in $2 \times$ SSC and $0.1 \%$ SDS once at room temperature for 20 minutes and in $0.1 \times \mathrm{SSC}$ and $0.1 \% \mathrm{SDS}$ at $65^{\circ} \mathrm{C} 3$ times for 15 minutes each. For confirming animal genotype, high-molecular weight genomic DNA was isolated from miniswine umbilicus. The remaining steps were performed as described above.

SCNT. Nuclear transfer was performed by Trans Ova Genetics (Sioux Center, Iowa, USA) as previously described (76). Embryo transfer was performed at Exemplar Genetics. Briefly, reconstructed oocytes were transferred into synchronized postpubertal domestic gilts on the first day of standing estrus. Recipient gilts were preanesthetized with i.v. propofol $(0.5-5 \mathrm{mg} / \mathrm{kg})$, and anesthesia was maintained with inhaled isoflurane $(3 \%-5 \%$ in oxygen via face mask). Following a midline incision to access the uterus, reconstructed embryos were transferred into the oviduct at the ampullary-isthmus junction. Intra- and postoperative analgesia was provided by i.m. injection of flunixin meglumine $(2.2 \mathrm{mg} / \mathrm{kg})$. Recipient animals were checked for pregnancy by abdominal ultrasound after day 21 and throughout gestation.

\section{Histopathological processing}

Tissues collection. Tissues were harvested for histopathology and placed into $10 \%$ neutral buffered formalin ( $\sim 3-6$ days) and were then routinely processed, paraffin embedded, and sectioned $(4 \mu \mathrm{m})$. Tissues were histochemically H\&E stained for routine examination, and special stains included Masson's trichome (77) for collagen, Sirius red (78) for eosinophils and collagen, and toluidine blue for mast cells. Immunostaining for cellular/tissue markers S100 and vWF were performed in swine tissues as recently described (79).

Morphometry. High-resolution digital images were collected and analyzed (BX51 microscope, DP73 digital camera and CellSens Software, Olympus). For histopathology morphometry, the pathologist (D.K. Meyerholz) utilized the postexamination method for masking to groups (80). For evaluation of macules, skin samples from NF1 macules were compared with adjacent nonmacule NF1 skin. Evaluation of melanocytes, high-resolution images were collected at 40× magnification of the epidermis and the linear extent of basement membrane was enumerated; then, the number of heavily pigmented cells were counted. The results were listed as the number of cells per length of basement membrane (number/mm). For the extent of neurovascular networks, high-resolution images at 40× magnification were collected, the dermis was quantified (total area), the neurovascular networks were manually defined, and the area was quantified. Results for neurovascular networks were reported as the percentage of total dermis area. 
Isolation and maintenance of swine fibroblasts

Ear or normal skin biopsies $(6-10 \mathrm{~mm})$ were obtained from miniswine rinsed in sterile PBS containing $1 \%$ penicillin-streptomycin solution (Corning) and were finely minced prior to overnight incubation at $37^{\circ} \mathrm{C}$ and $5 \% \mathrm{CO}_{2}$ in digestion media (DMEM containing 20\% heat-inactivated FBS, $1 \%$ penicillin-streptomycin, $0.25 \%$ collagenase type I [Worthington Biochemical], $0.05 \%$ DNAse I [MilliporeSigma]). The next day, digested samples were briefly vortexed, diluted 10-fold with swine fibroblast (PF) culture medium (DMEM, $20 \%$ FBS, $1 \%$ penicillin-streptomycin, $0.1 \mathrm{mM}$ nonessential amino acids), passed through $70-\mu \mathrm{m}$ nylon mesh, and plated in PF media into 2 wells of a 6-well collagen-coated plate with incubation at $37^{\circ} \mathrm{C}$ and $5 \%$ $\mathrm{CO}_{2}$. Cells were expanded for cryopreservation and maintained by serial passaging at approximately 1:4 dilution or $1 \times 10^{6}$ cells per $100 \mathrm{~mm}$ collagen-coated dish.

\section{Analyses of activated Ras signaling}

Western blotting and IHC staining were used to measure the cellular levels of phosphorylated Erk1/2, total Erk1/2, p53, and p21 proteins in unstimulated versus serum/growth factor-stimulated swine fibroblasts. Cells were grown to approximately $85 \%$ confluency and starved for 20-24 hours in DMEM containing $0.1 \%$ FBS. Cells were stimulated with DMEM containing $10 \% \mathrm{FBS}, 20 \mathrm{ng} / \mathrm{ml} \mathrm{bFGF}$, and $5 \mu \mathrm{g} / \mathrm{ml}$ insulin for the indicated times. For Western blotting, cells were washed in ice-cold PBS; scraped into lysis buffer (Cytoskeleton Inc.) containing protease and phosphatase inhibitors; clarified by centrifugation at $20,200 \mathrm{x} g, 4^{\circ} \mathrm{C}$ for 2 minutes; and flash frozen in LN2. Thawed lysates were quantified using Precision Red protein assay (Cytoskeleton Inc.) and $50 \mu \mathrm{g}$ of protein from each sample was separated by SDS-PAGE and transferred onto PVDF membranes (MilliporeSigma). Antibodies used for immunoblotting included those against neurofibromin (Abcam, 17963, 1:1,000), phosphorylated Erk1/2 at Thr202/Tyr204 (Cell Signaling, 9106, 1:1,000), total Erk1/2 (Cell Signaling Technologies, 4695, 1:1,000), total Ras (Cell Signaling Technologies, 3965, 1:1,000), and p16INK4a (made in house) (affinity purified rabbit polyclonal antibody made against porcine peptide $\left[\mathrm{NH}_{2}\right.$-CRTEGGSHARSNSGEDPAD-COOH], used at $6 \mu \mathrm{g} / \mathrm{ml}$ ). For IHC analyses, starved cells were left untreated or stimulated for 30 minutes, harvested by brief trypsinization, and collected into the same treatment media containing $1 \%$ BSA. Pelleted cells were washed briefly in PBS, pelleted, and fixed in $10 \%$ neutral buffered formalin prior to paraffin embedding. Samples were immunolabeled with previously described techniques (41, 79) using antibodies listed above as well antibodies against p53 (Santa Cruz Biotechnology Inc., DO-1), p21 (BD Pharmingen, 554228), and SIAH (24E6H3 mouse monoclonal antibody; ref.45).

\section{RT-PCR method}

Total cellular RNA was extracted from primary tissue and cultured cells using the Trizol system (Thermo Fisher Scientific). Reverse transcription of $1 \mu \mathrm{g}$ of RNA was carried out using the Superscript II system with random hexamers (Thermo Fisher Scientific). PCR amplification of the NfI gene flanking the KO mutation utilized standard hot-start Taq polymerase conditions (60 degrees annealing) and the following primers: forward E29c5 5'- CTCACCTTCATGCACCAGGAG -3' and reverse TBR5A 5'- CACCTGTTGCACTGGTTTTGATG -3', whose sequences are completely conserved between human and swine. The WT allele PCR product is $637 \mathrm{bp}$, and the Nf1 pig mutation (deletion of 1 exon) results in a PCR product of $443 \mathrm{bp}$ in length; products were separated using $8 \%$ native polyacrylamide gel electrophoresis and visualized with ethidium bromide staining.

\section{Neurobehavior testing}

Simple T-maze. The 15-feet squared apparatus consisted of a holding pen and retractable gate guided by a pulley, allowing the observer to easily lift the door to initiate the test while out of the miniswine's line of site (Figure 5A). The opening to each arm contained a removable sliding gate that was used to close off the arm not chosen by the animal. Each arm contained 1 black, rubber feed bowl that either contained a reward (vanilla pudding or Purina UltraCare Gel, depending on the animal's preference) or nothing. Each arm contained a unique visual cue as an additional learning cue. Video recording of animals as they navigated through the maze was not possible due to the short height of the ceiling and the large size of the apparatus; consequently, animals were manually recorded by the observer throughout each test.

Left-right discrimination task. Modified from Elmore et al., the left-right discrimination task is a measure of learning and reference memory (81). Prior to the acquisition phase, animals were first acquainted to the apparatus and food reward for 10 minutes a day for 2 days. The animals were then subsequently conditioned to the task for an additional 2 days. The first of these conditioning days consisted of ten 60 -second 
trials where the animal was allowed to explore the apparatus and consume the food reward regardless of which arm was chosen. The second of these conditioning days consisted of ten 60-second trials, as well. Here, the first 5 trials were identical to the first day of conditioning, where the animal was allowed to consume the reward regardless of the arm chosen. The last 5 trials, however, were meant to train the animal to the actual task, and the animal was only allowed to consume the food reward if the correct arm was chosen. After a total of 4 days of training, the animals were then moved to the first phase of testing: the acquisition phase. During the acquisition phase, animals were given ten 60 -second trials where they were free to choose an arm. The food reward was only consumed if the arm containing the reward was chosen. The arm chosen and time to choose the arm were recorded manually by the observer, and the apparatus was thoroughly cleaned between each trial to minimize odor cues. This protocol was repeated daily until all animals identified the correct reward arm with $80 \%$ accuracy, which allowed the animals to move to the reversal phase. In this phase, the food reward was moved to the opposite arm and animals were given ten 60 -second trials daily for 2 days. The food reward was only consumed if the arm containing the reward was chosen, and the arm chosen and time to choose the arm were recorded manually by the observer.

Unfamiliar-object task. Unfamiliar object exploration tasks can be used as measures of anxiety and hyperactivity. On day 1, animals were placed in a clean pen for 10 minutes with an unfamiliar object hanging from the ceiling by wire. The time to first touch the object (and make the wire move) as well as the time spent physically interacting with the object were manually recorded by an observer. On day 2, animals were placed in a clean pen for 10 minutes with 2 objects hanging from the ceiling: 1 unfamiliar object and the object from the day before. The time to first touch the objects and time spent physically interacting with the objects were manually recorded by an observer. Once again, due to the low ceiling height of the building, video recording of the pen was not possible. With this limitation in mind, the choice to hang the object from the ceiling was made, as this allowed the observer to remain out of the animal's line of sight while still manually recording physical interactions with the object using the movement of the wire. This does limit this test to strictly physical interactions, and noncontact interactions such as sniffing cannot be inferred.

Imaging

Animal preparation. All procedures were performed under anesthesia, induced with either telazol (2.2 mg/ $\mathrm{kg})$, ketamine $(1.1 \mathrm{mg} / \mathrm{kg})$, and xylazine $(1.1 \mathrm{mg} / \mathrm{kg})$ or with midazolam $(0.3 \mathrm{mg} / \mathrm{kg})$ and ketamine $(8 \mathrm{mg} /$ $\mathrm{kg})$. Anesthesia was maintained with isoflurane $(1.5 \%-5 \%)$ via nose cone or balloon cuffed tracheal tube ( $8 \mathrm{~mm}$ ). Mechanical ventilation at $100 \%$ oxygen and tidal volume of $10 \mathrm{ml} / \mathrm{kg}$ with a $5 \mathrm{cmH}_{2} \mathrm{O}$ positive end expiratory pressure was achieved with a Primer SP MRI-Compatible Veterinary Anesthesia Ventilator (DRE Veterinary). Peripheral i.v. access was obtained via a 20 -gauge ear vein cannula for administration of contrast during imaging and patency maintained with heparinized saline (500 U/1). After data collection, animals were recovered from anesthesia and returned to the long-term housing facility.

MRI. MRI was performed using a research-dedicated Discovery MR750w 3.0T scanner (GE Healthcare). Brain imaging was acquired using a T1-weighted (BRAVO) and T2-weighted sequence (both with resolution of $0.8 \mathrm{~mm} \times 0.8 \mathrm{~mm} \times 1 \mathrm{~mm}$ slice thickness $)$, as well as a FLAIR sequence $(0.4 \mathrm{~mm} \times 0.4 \mathrm{~mm} \times 2 \mathrm{~mm}$ slice thickness). Imaging of the body included axial T1-weighted (STIR), T2-weighted (with fat saturation), and a volume interpolated gradient echo (LAVA) protocol acquired before and after administration of $0.1 \mathrm{mmol} / \mathrm{kg}$ gadolinium contrast (Dotarem, Guerbet). Bidimensional lesion measurements, taken as the longest perpendicular diameters, were acquired from the MRI data in the axial cross-section for each lesion.

Biopsy. Animals were prepared and anesthetized as described above, and in addition prior to the procedure, i.m. delivery analgesia was administered (carprofen, $2 \mathrm{mg} / \mathrm{kg}$ ). Following surgical preparation of the biopsy site, a wedge-shaped biopsy sample was removed with a scalpel from each lesion. The biopsy samples were taken at a depth reaching under the epidermis, extending from the center of the lesion to the periphery to include a small margin of normal tissue. Sutures were used to close the incision sites and were removed 7 days after the procedure.

\section{DRG analysis}

Culturing and transfection of swine DRG neurons. DRG neurons were isolated from 4-month-old ( $n=13$ for WT and $n=10$ for $N F 1^{+/ \text {ex42de })}$ Yucatan miniswine using a variation of previously developed procedures (82). In brief, dorsal skin and muscle were removed using a knife to expose the vertebral column in the miniswine. Vertebral bone processes were cut using custom-made pliers, parallel to the dissection stage to 
expose the spinal cord. DRGs were then collected, trimmed at their roots, and digested in $3 \mathrm{ml}$ bicarbonatefree, serum-free, sterile DMEM solution (catalog 11965, Thermo Fisher Scientific) containing neutral protease (3.125 mg. $\mathrm{ml}^{-1}$, catalog LS02104, Worthington) and collagenase type I (5 mg. ml ${ }^{-1}$, catalog LS004194, Worthington) and incubated for $45-75$ minutes at $37^{\circ} \mathrm{C}$ under gentile agitation. Dissociated DRG neurons $\left(\sim 1.5 \times 10^{6}\right)$ were then gently centrifuged to collect cells and washed with and grown in DRG media DMEM containing $1 \%$ penicillin/streptomycin sulfate from $10,000 \mu \mathrm{g} / \mathrm{ml} \mathrm{stock,} 30 \mathrm{ng} \cdot \mathrm{ml}^{-1}$ nerve growth factor, and 10\% FBS (Hyclone). All cultures were used 48 hours after transfection.

Calcium imaging in acutely dissociated miniswine DRG neurons. DRG neurons were loaded for 30 minutes at $37^{\circ} \mathrm{C}$ with $3 \mu \mathrm{M}$ Fura-2AM (catalog F1221, Thermo Fisher Scientific; stock solution prepared at $1 \mathrm{mM}$ in DMSO, $0.02 \%$ pluronic acid, catalog P-3000MP, Invitrogen) to survey changes in intracellular calcium $\left(\left[\mathrm{Ca}^{2+}\right]_{\mathrm{c}}\right)$ in a standard bath solution containing $139 \mathrm{mM} \mathrm{NaCl}, 3 \mathrm{mM} \mathrm{KCl}, 0.8 \mathrm{mM} \mathrm{MgCl} 2,1.8$ $\mathrm{mM} \mathrm{CaCl}, 10 \mathrm{mM} \mathrm{NaHEPES}, \mathrm{pH} 7.4$, and $5 \mathrm{mM}$ glucose exactly as previously described (82). Fluorescence imaging was performed with an inverted microscope, Nikon Eclipse TE2000-U, using objective Nikon Super Fluor 20× 0.75 NA and a Photometrics cooled CCD camera CoolSNAPHQ (Roper Scientific) controlled by MetaFluor 6.3 software (Molecular Devices). The excitation light was delivered by a Lambda-LS system (Sutter Instruments). The excitation filters (340 $\pm 5 \mathrm{~nm}$ and $380 \pm 7 \mathrm{~nm}$ ) were controlled by a Lambda 10-2 optical filter change (Sutter Instruments). Fluorescence was recorded through a $505-\mathrm{nm}$ dichroic mirror at $535 \pm 25 \mathrm{~nm}$. To minimize photobleaching and phototoxicity, the images were taken about every 5 seconds during the time course of the experiment using the minimal exposure time that provided acceptable image quality. The changes in $\left[\mathrm{Ca}^{2+}\right]_{\mathrm{c}}$ were monitored by following a ratio of F340/F380, calculated after subtracting the background from both channels.

Whole-cell patch recordings of $\mathrm{Na}^{+}$currents in acutely dissociated miniswine DRG neurons. Recordings were obtained from acutely dissociated miniswine DRG neurons as described. Whole cell voltage clamp recordings were performed at room temperature using an EPC 10 Amplifier-HEKA as previously described (83). The internal solution for voltage clamp sodium current recordings contained (in $\mathrm{mM}$ ): $140 \mathrm{CsF}$, 1.1Cs-EGTA, $10 \mathrm{NaCl}$, and $15 \mathrm{HEPES}$ ( $\mathrm{pH} 7.3,290-310 \mathrm{mOsm} / 1$ ). It also included external solution, which contained (in $\mathrm{mM}$ ): $140 \mathrm{NaCl}, 3 \mathrm{KCl}, 30$ tetraethylammonium chloride, 1 $\mathrm{CaCl}_{2}, 0.5 \mathrm{CdCl}_{2}, 1 \mathrm{MgCl}_{2}, 10 \mathrm{D}$-glucose, $10 \mathrm{HEPES}$ ( $\mathrm{pH} 7.3,310-315 \mathrm{mOsm} / 1$ ). DRG neurons were subjected to current-density (I-V) voltage protocols as previously described $(81,82)$. In the I-V protocol, cells were held at a $-80 \mathrm{mV}$ holding potential prior to depolarization by $20 \mathrm{~ms}$ voltage steps from $-70 \mathrm{mV}$ to $+60 \mathrm{mV}$ in $5-\mathrm{mV}$ increments. This allowed for collection of current density data to analyze activation of sodium channels as a function of current versus voltage and also peak current density, which was typically observed near $\sim 0-10 \mathrm{mV}$ and normalized to cell capacitance (pF). The capacitances (in picoFarads; $\mathrm{pF}$ ) of the DRGs were: $102.0 \pm 8.9 \mathrm{pF}(n=12)$ for WT and $125.0 \pm 20.0$ $\mathrm{pF}(n=10)(P>0.05 ; 2$ tailed Student's $t$ test; $t=1.1174, d f=20$, standard error of difference $=20.6)$.

\section{Statistics}

Statistics were performed using GraphPad Prism 6.04. Specific statistical test information is indicated in the figure legends. For histopathology experiments of café au lait macules, a paired, 2-tailed Student's $t$ test was performed. For electrophysiology experiments and unfamiliar-object experiments, unpaired, 2-tailed Student's $t$ tests were performed. For the T-maze experiment, a 2-tailed Mann-Whitney $U$ test was performed. ${ }^{*} P<0.05,{ }^{* *} P<0.01,{ }^{* * *} P<0.001,{ }^{* * * *} P<0.0001$.

\section{Study approval}

All animals were maintained at Exemplar Genetics under an approved IACUC protocol (protocol no. MRP2016-009). Imaging and biopsy procedures were conducted at the University of Iowa in accordance with the IACUC approved protocol (Office of Animal Resources, University of Iowa; protocol no. 7061269).

\section{Author contributions}

CHC, CSR, FAR, and JMW conceived and created the animal model. CSR, FAR, DKM, DEQ, MRW, RDD, JTC, RK, KP, BWD, JCS, and JMW contributed to study design. DKM, AHT, AG, MRT, and MRL conceived and performed histopathology experiments. DEQ, JLK, SU, and HL conceived and performed cellular assays. JMW, KAW, and FAR conceived and performed neurobehavior experiments. FAR and KAW monitored animal health and presentation. JCS, JU, and EH conceived and performed imaging 
experiments. RK, AM, SC, WL, and SSB conceived and performed electrophysiology experiments. VJS, KAW, DKM, MRW, RK, RDD, BWD, KP, CSR, JCS, DEQ, and JMW contributed to writing of the manuscript. All authors reviewed and approved of the final manuscript.

\section{Acknowledgments}

We would like to acknowledge the following individuals for technical assistance: Judy Rohret, Jason Struzynski, Bryan Davis, Xiaojun Wang, Brian Dacken, Dan Thedens, Marla Kleingartner, Autumn Craig, Kori Rich, Courtney Kaemmer, and Trisha Smit. This work was supported by funding from the Synodos for NF1 program at the Children's Tumor Foundation to DKM, BWD, CSR, JCS, DEQ, and JMW; a research award from the Children's Tumor Foundation (2015-04-009A) to RK and JMW; a grant from the NIH to JMW (R01NS082283); a Neurofibromatosis New Investigator Award from the US Department of Defense Congressionally Directed Military Medical Research and Development Program (NF1000099) to RK; NIH awards (1R01NS098772 and 1R01DA042852) to RK; and an NCI Core grant (P30-CA086862) to the University of Iowa Holden Comprehensive Cancer Center. The MR system used in this study is supported by a NIH shared instrumentation award (1S10OD02502501). JLK was supported by a Pharmacological Sciences Training grant (2T32-GM0677954-14). AM was supported by a Young Investigator's Award from the Children's Tumor Foundation. SSB was supported by funds to the University of Arizona's Undergraduate Biology Research Program.

Address correspondence to: Chris Rogers, Exemplar Genetics, PO Box 198, Sioux Center, Iowa, USA. Phone: 712.722.2767; Email: Chris.Rogers@exemplargenetics.com. Or to: Jessica Sieren, 200 Hawkins Drive, CC-704 GH, Iowa City, Iowa 52242, USA. Phone: 319.356.1407; Email: Jessica-Sieren@uiowa.edu. Or to: Dawn Quelle, University of Iowa, 2-570 Bowen Science Building, 52 Newton Road, Iowa City, 52242 1109, Iowa, USA. Phone: 319.353.5749; Email: dawn-quelle@uiowa.edu. Or to: Jill Weimer; 2301 E 60th St N, Sioux Falls, South Dakota, 57104, USA. Phone: 605.312.6300; Email: Jill.Weimer@SanfordHealth.org.

1. Viskochil D, et al. Deletions and a translocation interrupt a cloned gene at the neurofibromatosis type 1 locus. Cell. 1990;62(1):187-192.

2. Wallace MR, et al. Type 1 neurofibromatosis gene: identification of a large transcript disrupted in three NF1 patients. Science. 1990;249(4965):181-186.

3. Golubić M, et al. The GTPase stimulatory activities of the neurofibromatosis type 1 and the yeast IRA2 proteins are inhibited by arachidonic acid. EMBO J. 1991;10(10):2897-2903.

4. Gutmann DH, Collins FS. The neurofibromatosis type 1 gene and its protein product, neurofibromin. Neuron. 1993;10(3):335-343.

5. Basu TN, Gutmann DH, Fletcher JA, Glover TW, Collins FS, Downward J. Aberrant regulation of ras proteins in malignant tumour cells from type 1 neurofibromatosis patients. Nature. 1992;356(6371):713-715.

6. DeClue JE, et al. Abnormal regulation of mammalian p21ras contributes to malignant tumor growth in von Recklinghausen (type 1) neurofibromatosis. Cell. 1992;69(2):265-273.

7. Johnson B. Cognitive dysfunction, gait, and motor impairment in neurofibromatosis type 1. Dev Med Child Neurol. 2014;56(5):415.

8. Krab LC, et al. Motor learning in children with neurofibromatosis type I. Cerebellum. 2011;10(1):14-21.

9. Riccardi VM. Type 1 neurofibromatosis and the pediatric patient. Curr Probl Pediatr. 1992;22(2):66-106; discussion 107.

10. Ozonoff S. Cognitive impairment in neurofibromatosis type 1. Am J Med Genet. 1999;89(1):45-52.

11. Rosenfeld A, Listernick R, Charrow J, Goldman S. Neurofibromatosis type 1 and high-grade tumors of the central nervous system. Childs Nerv Syst. 2010;26(5):663-667.

12. Friedman JM. Epidemiology of neurofibromatosis type 1. Am J Med Genet. 1999;89(1):1-6.

13. Boyd KP, Korf BR, Theos A. Neurofibromatosis type 1. J Am Acad Dermatol. 2009;61(1):1-14; quiz 15.

14. Brannan CI, et al. Targeted disruption of the neurofibromatosis type-1 gene leads to developmental abnormalities in heart and various neural crest-derived tissues. Genes Dev. 1994;8(9):1019-1029.

15. Jacks T, Shih TS, Schmitt EM, Bronson RT, Bernards A, Weinberg RA. Tumour predisposition in mice heterozygous for a targeted mutation in Nf1. Nat Genet. 1994;7(3):353-361.

16. Upadhyaya M, Cooper DN. In: Upadhyaya M, Cooper DN eds. NF1: From Genotype To Phenotype. Oxford: BIOS Publishers; 1998:65-88

17. Zhu Y, et al. Ablation of NF1 function in neurons induces abnormal development of cerebral cortex and reactive gliosis in the brain. Genes Dev. 2001;15(7):859-876.

18. O'Brien DE, Brenner DS, Gutmann DH, Gereau RW. Assessment of pain and itch behavior in a mouse model of neurofibromatosis type 1. J Pain. 2013;14(6):628-637

19. Cichowski K, Jacks T. NF1 tumor suppressor gene function: narrowing the GAP. Cell. 2001;104(4):593-604.

20. Parada LF, Kwon CH, Zhu Y. Modeling neurofibromatosis type 1 tumors in the mouse for therapeutic intervention. Cold Spring Harb Symp Quant Biol. 2005;70:173-176.

21. Cichowski K, et al. Mouse models of tumor development in neurofibromatosis type 1. Science. 1999;286(5447):2172-2176. 
22. Dodd RD, et al. NF1 deletion generates multiple subtypes of soft-tissue sarcoma that respond to MEK inhibition. Mol Cancer Ther. 2013;12(9):1906-1917.

23. Vogel KS, Klesse LJ, Velasco-Miguel S, Meyers K, Rushing EJ, Parada LF. Mouse tumor model for neurofibromatosis type 1. Science. 1999;286(5447):2176-2179.

24. Joseph NM, et al. The loss of Nf1 transiently promotes self-renewal but not tumorigenesis by neural crest stem cells. Cancer Cell. 2008;13(2):129-140.

25. Huang J, et al. Generation and comparison of CRISPR-Cas9 and Cre-mediated genetically engineered mouse models of sarcoma. Nat Commun. 2017;8:15999.

26. Shilyansky C, et al. Neurofibromin regulates corticostriatal inhibitory networks during working memory performance. Proc Natl Acad Sci USA. 2010;107(29):13141-13146.

27. Costa RM, et al. Learning deficits, but normal development and tumor predisposition, in mice lacking exon 23a of Nf1. Nat Genet. 2001;27(4):399-405.

28. Prather RS, Lorson M, Ross JW, Whyte JJ, Walters E. Genetically engineered pig models for human diseases. Annu Rev Anim Biosci. 2013;1:203-219.

29. Rogers CS, et al. The porcine lung as a potential model for cystic fibrosis. Am J Physiol Lung Cell Mol Physiol. 2008;295(2):L240-L263

30. Meyerholz DK, et al. Loss of cystic fibrosis transmembrane conductance regulator function produces abnormalities in tracheal development in neonatal pigs and young children. Am J Respir Crit Care Med. 2010;182(10):1251-1261.

31. Meyerholz DK, Stoltz DA, Pezzulo AA, Welsh MJ. Pathology of gastrointestinal organs in a porcine model of cystic fibrosis. Am J Pathol. 2010;176(3):1377-1389.

32. Stoltz DA, et al. Cystic fibrosis pigs develop lung disease and exhibit defective bacterial eradication at birth. Sci Transl Med 2010;2(29):29ra31.

33. Beraldi R, et al. A novel porcine model of ataxia telangiectasia reproduces neurological features and motor deficits of human disease. Hum Mol Genet. 2015;24(22):6473-6484.

34. Davis BT, et al. Targeted disruption of LDLR causes hypercholesterolemia and atherosclerosis in Yucatan miniature pigs. PLoS One. 2014;9(4):e93457

35. Park DS, et al. Genetically engineered SCN5A mutant pig hearts exhibit conduction defects and arrhythmias. J Clin Invest. 2015;125(1):403-412.

36. Sieren JC, et al. Development and translational imaging of a TP53 porcine tumorigenesis model. J Clin Invest. 2014;124(9):4052-4066

37. Rogers CS, et al. Production of CFTR-null and CFTR-DeltaF508 heterozygous pigs by adeno-associated virus-mediated gene targeting and somatic cell nuclear transfer. J Clin Invest. 2008;118(4):1571-1577.

38. Serrano M, Lin AW, McCurrach ME, Beach D, Lowe SW. Oncogenic ras provokes premature cell senescence associated with accumulation of p53 and p16INK4a. Cell. 1997;88(5):593-602.

39. Sherr CJ. The INK4a/ARF network in tumour suppression. Nat Rev Mol Cell Biol. 2001;2(10):731-737.

40. Collado M, Blasco MA, Serrano M. Cellular senescence in cancer and aging. Cell. 2007;130(2):223-233.

41. Ahmed AU, et al. Effect of disrupting seven-in-absentia homolog 2 function on lung cancer cell growth. J Natl Cancer Inst. 2008;100(22):1606-1629.

42. Schmidt RL, et al. Inhibition of RAS-mediated transformation and tumorigenesis by targeting the downstream E3 ubiquitin ligase seven in absentia homologue. Cancer Res. 2007;67(24):11798-11810.

43. Silva AJ, et al. A mouse model for the learning and memory deficits associated with neurofibromatosis type I. Nat Genet. $1997 ; 15(3): 281-284$

44. Hyman SL, Shores A, North KN. The nature and frequency of cognitive deficits in children with neurofibromatosis type 1. Neurology. 2005;65(7):1037-1044.

45. Mautner VF, Kluwe L, Thakker SD, Leark RA. Treatment of ADHD in neurofibromatosis type 1. Dev Med Child Neurol. 2002;44(3):164-170.

46. Piscitelli O, Digilio MC, Capolino R, Longo D, Di Ciommo V. Neurofibromatosis type 1 and cerebellar T2-hyperintensities: the relationship to cognitive functioning. Dev Med Child Neurol. 2012;54(1):49-51.

47. Lim R, Jaramillo D, Poussaint TY, Chang Y, Korf B. Superficial neurofibroma: a lesion with unique MRI characteristics in patients with neurofibromatosis type 1. AJR Am J Roentgenol. 2005;184(3):962-968.

48. Bassi B, Vannelli S, Giraudo MC, Burdino E, Rigardetto R. [Unidentified bright objects and neuropsychiatric disturbances]. Minerva Pediatr. 2013;65(4):371-381.

49. Billiet T, et al. Characterizing the microstructural basis of "unidentified bright objects" in neurofibromatosis type 1: A combined in vivo multicomponent T2 relaxation and multi-shell diffusion MRI analysis. Neuroimage Clin. 2014;4:649-658.

50. Ferraz-Filho JR, José da Rocha A, Muniz MP, Souza AS, Goloni-Bertollo EM, Pavarino-Bertelli EC. Unidentified bright objects in neurofibromatosis type 1: conventional MRI in the follow-up and correlation of microstructural lesions on diffusion tensor images. Eur J Paediatr Neurol. 2012;16(1):42-47.

51. Jouhilahti EM, Peltonen S, Heape AM, Peltonen J. The pathoetiology of neurofibromatosis 1. Am J Pathol. 2011;178(5):1932-1939.

52. Duan JH, Hodgdon KE, Hingtgen CM, Nicol GD. N-type calcium current, Cav2.2, is enhanced in small-diameter sensory neurons isolated from Nf1+/- mice. Neuroscience. 2014;270:192-202.

53. Moutal A, et al. CRISPR/Cas9 editing of Nf1 gene identifies CRMP2 as a therapeutic target in neurofibromatosis type 1-related pain that is reversed by (S)-Lacosamide. Pain. 2017;158(12):2301-2319.

54. Wang Y, Duan JH, Hingtgen CM, Nicol GD. Augmented sodium currents contribute to the enhanced excitability of small diameter capsaicin-sensitive sensory neurons isolated from Nf1+/- mice. J Neurophysiol. 2010;103(4):2085-2094.

55. Moutal A, Cai S, Luo S, Voisin R, Khanna R. CRMP2 is necessary for Neurofibromatosis type 1 related pain. Channels (Austin). 2018;12(1):47-50.

56. Moutal A, Dustrude ET, Khanna R. Sensitization of Ion Channels Contributes to Central and Peripheral Dysfunction in Neurofibromatosis Type 1. Mol Neurobiol. 2017;54(5):3342-3349.

57. Wang Y, Nicol GD, Clapp DW, Hingtgen CM. Sensory neurons from Nf1 haploinsufficient mice exhibit increased excitability. 
J Neurophysiol. 2005;94(6):3670-3676.

58. Gutmann DH, Giovannini M. Mouse models of neurofibromatosis 1 and 2. Neoplasia. 2002;4(4):279-290.

59. Golblum JR, Weiss SW, Flope AL. Enzinger \& Weiss's Soft Tissue Tumors. Philadelphia, PA: Elsevier Saunders; 2014.

60. Lim R, Jaramillo D, Poussaint TY, Chang Y, Korf B. Superficial neurofibroma: a lesion with unique MRI characteristics in patients with neurofibromatosis type 1. AJR Am J Roentgenol. 2005;184(3):962-968.

61. McCarron KF, Goldblum JR. Plexiform neurofibroma with and without associated malignant peripheral nerve sheath tumor: a clinicopathologic and immunohistochemical analysis of 54 cases. Mod Pathol. 1998;11(7):612-617.

62. Tonsgard JH. Clinical manifestations and management of neurofibromatosis type 1. Semin Pediatr Neurol. 2006;13(1):2-7.

63. Hersh JH, American Academy of Pediatrics Committee on Genetics. Health supervision for children with neurofibromatosis. Pediatrics. 2008;121(3):633-642.

64. Dombi E, et al. Recommendations for imaging tumor response in neurofibromatosis clinical trials. Neurology. 2013;81(21 Suppl 1):S33-S40

65. Widemann BC, et al. Conclusions and future directions for the REiNS International Collaboration. Neurology. 2013;81(21 Suppl 1):S41-S44

66. Torres Nupan MM, Velez Van Meerbeke A, López Cabra CA, Herrera Gomez PM. Cognitive and Behavioral Disorders in Children with Neurofibromatosis Type 1. Front Pediatr. 2017;5:227.

67. Silva AJ, et al. A mouse model for the learning and memory deficits associated with neurofibromatosis type I. Nat Genet. $1997 ; 15(3): 281-284$

68. Cui Y, et al. Neurofibromin regulation of ERK signaling modulates GABA release and learning. Cell. 2008;135(3):549-560.

69. Gottfried ON, Viskochil DH, Couldwell WT. Neurofibromatosis Type 1 and tumorigenesis: molecular mechanisms and therapeutic implications. Neurosurg Focus. 2010;28(1):E8

70. Ratner N, Miller SJ. A RASopathy gene commonly mutated in cancer: the neurofibromatosis type 1 tumour suppressor. Nat Rev Cancer. 2015;15(5):290-301.

71. Dombi E, et al. Activity of Selumetinib in Neurofibromatosis Type 1-Related Plexiform Neurofibromas. NEngl J Med. 2016;375(26):2550-2560.

72. Benemei S, Nicoletti P, Capone JG, Geppetti P. CGRP receptors in the control of pain and inflammation. Curr Opin Pharmacol. 2009;9(1):9-14.

73. Hingtgen CM, Roy SL, Clapp DW. Stimulus-evoked release of neuropeptides is enhanced in sensory neurons from mice with a heterozygous mutation of the Nf1 gene. Neuroscience. 2006;137(2):637-645.

74. Wang Y, Brittain JM, Wilson SM, Hingtgen CM, Khanna R. ALTERED CALCIUM CURRENTS AND AXONAL GROWTH IN Nf1 HAPLOINSUFFICIENT MICE. Transl Neurosci. 2010;1(2):106-114.

75. McCreath KJ, Howcroft J, Campbell KH, Colman A, Schnieke AE, Kind AJ. Production of gene-targeted sheep by nuclear transfer from cultured somatic cells. Nature. 2000;405(6790):1066-1069.

76. Walker SC, et al. A highly efficient method for porcine cloning by nuclear transfer using in vitro-matured oocytes. Cloning Stem Cells. 2002;4(2):105-112.

77. Cook DP, et al. Mounier-Kuhn syndrome: a case of tracheal smooth muscle remodeling. Clin Case Rep. 2017;5(2):93-96.

78. Meyerholz DK, Griffin MA, Castilow EM, Varga SM. Comparison of histochemical methods for murine eosinophil detection in an RSV vaccine-enhanced inflammation model. Toxicol Pathol. 2009;37(2):249-255.

79. Meyerholz DK, et al. Immunohistochemical Markers for Prospective Studies in Neurofibromatosis-1 Porcine Models. J Histochem Cytochem. 2017;65(10):607-618

80. Gibson-Corley KN, Olivier AK, Meyerholz DK. Principles for valid histopathologic scoring in research. Vet Pathol. 2013;50(6):1007-1015.

81. Elmore MR, Dilger RN, Johnson RW. Place and direction learning in a spatial T-maze task by neonatal piglets. Anim Cogn. 2012;15(4):667-676

82. Brittain JM, et al. Suppression of inflammatory and neuropathic pain by uncoupling CRMP-2 from the presynaptic Ca ${ }^{2+}$ channel complex. Nat Med. 2011;17(7):822-829.

83. Dustrude ET, Wilson SM, Ju W, Xiao Y, Khanna R. CRMP2 protein SUMOylation modulates NaV1.7 channel trafficking. $J$ Biol Chem. 2013;288(34):24316-24331. 